\title{
Computational fluid dynamics modelling of non-premixed combustion in direct injection diesel engines
}

\author{
H Barths, C Hasse and N Peters \\ Institut für Technische Mechanik, \\ RWTH Aachen, Germany
}

Received 30 May 2000

\begin{abstract}
An overview over flamelet modelling for turbulent non-premixed combustion is given. A short review of previous contributions to simulations of direct injection (DI) diesel engine combustion using the representative interactive flamelet concept is presented. A surrogate fuel consisting of 70 per cent (liquid volume) $n$-decane and 30 per cent $\alpha$-methyl-naphthalene is experimentally compared to real diesel fuel. The resemblance of their physical and chemical properties is shown to result in very similar combustion and pollutant formation for both fuels.

In order to account for variations of the scalar dissipation rate within the computational domain, a method using multiple flamelets, called the Eulerian particle flamelet model, is used. A strategy is described for subdividing the computational domain and assigning the resulting subdomains to different flamelet histories represented by Eulerian marker particles. Experiments conducted with an Audi DI diesel engine and diesel fuel are compared to simulations using the surrogate fuel. The use of multiple flamelets, each having a different history, significantly improves the description of the ignition phase, leading to a better prediction of pressure, heat release and exhaust emissions of soot and $\mathrm{NO}_{x}$. The effect of the number of flamelet particles on the predictions is discussed.
\end{abstract}

Key words: CFD modelling, diesel engines, combustion, flamelet, emissions

\section{Introduction}

First the representative interactive flamelet (RIF) concept was applied to a spray in a high-pressure, hightemperature combustion bomb by Pitsch et al. [1]. Their paper focused on soot formation and oxidation under diesel engine conditions using $n$-heptane as fuel. In 1996 Pitsch et al. [2] investigated the pollutant formation in a Volkswagen direct injection (DI) diesel engine, also fuelled with $n$-heptane. Different exhaust gas recirculation (EGR) rates were considered and the well-known trade-off between $\mathrm{NO}_{x}$ and soot was reproduced by the simulations. The significance of the scalar dissipation rate representing strain effects on the ignition and combustion process, especially the ignition delay time, was shown.

Barths et al. [3] compared results of simulations using an eddy dissipation model [4] in combination with the extended Zel'dovich $\mathrm{NO}_{x}$ mechanism and the Hiroyasu soot model [5] (see the Appendix) to those obtained with the RIF model. The tuning parameters (for ignition and combustion) in the former models were adjusted for the baseline case ( 0 per cent EGR) and then held constant. The constants for the $\mathrm{NO}_{x}$ and soot models were set as recommended by Belardini et al. [6]. The trade-off curves for both models and the experiments are shown in Fig. 1.

The RIF model predicts the $\mathrm{NO}_{x}$ emissions very well and slightly over-predicts the soot emissions, which, however, are still in the correct order of magnitude. The trends for $\mathrm{NO}_{x}$ and soot are also well reproduced. The Magnussen model [4] shows a significantly stronger decrease of the $\mathrm{NO}_{x}$ emissions on the EGR rate than the experiment. The extended Zel'dovic mechanism only accounts for thermal NO, and therefore misses contributions from other mechanisms (see below) that contribute to $\mathrm{NO}_{x}$ formation. The soot emissions are overpredicted by more than an order of magnitude, although they show the right dependence on the EGR rate. The parameters of the Hiroyasu soot model could have been adjusted to 


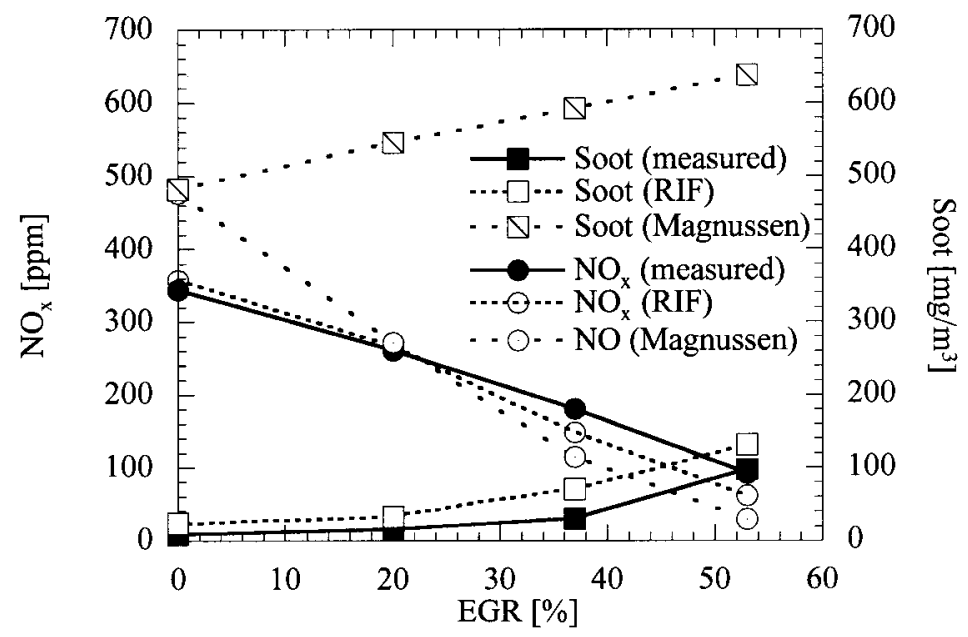

Fig. 1 Computed and measured exhaust gas concentrations of $\mathrm{NO}_{x}$ and soot mass for different EGR rates.

yield better results, but it was not the aim of that work to calibrate this model. The contributions of the different reaction paths to the NO production in the RIF model of 0 and 53 per cent EGR are shown in Figs 2 and 3 respectively.
For 0 per cent EGR thermal NO is the dominating production path. Prompt NO contributes less than 5 per cent to the overall NO formation. After the partially premixed burning phase at around $3^{\circ} \mathrm{CA}$ ATDC (crank angle after top dead centre) the nitrous

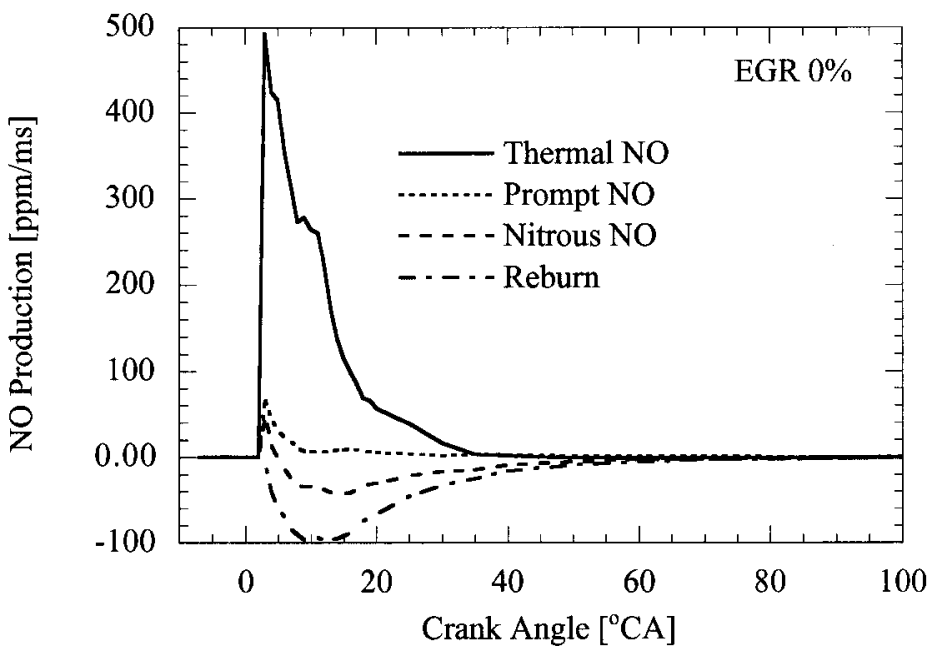

Fig. 2 NO production computed by the RIF model for 0 per cent EGR.

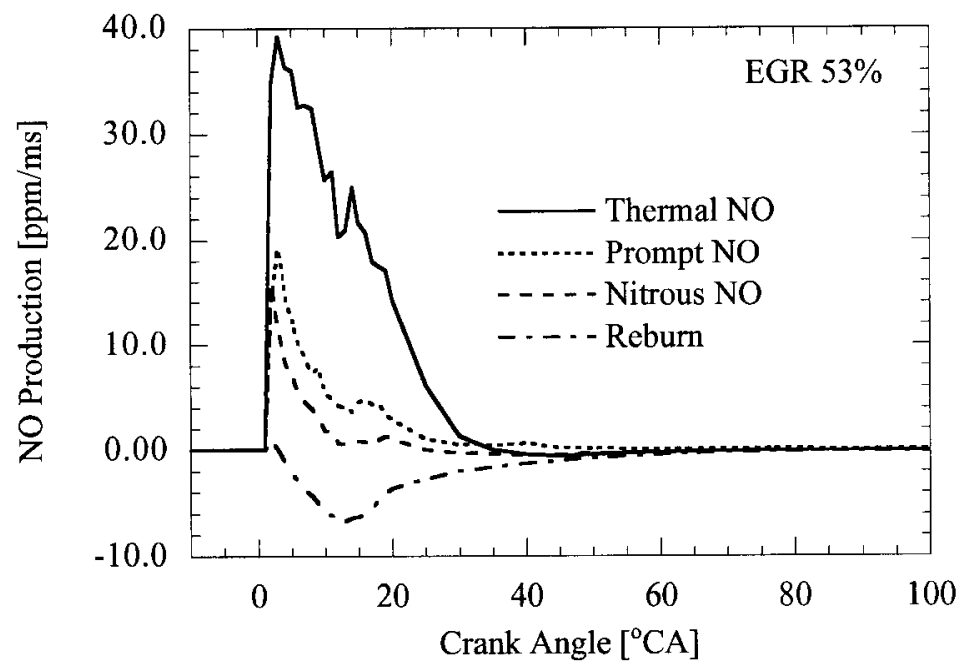

Fig. 3 NO production computed by the RIF model for 53 per cent EGR. 
oxide and reburn paths began to reduce the $\mathrm{NO}$ concentration until the reactions ceased at about $50^{\circ}$ CA ATDC. Therefore the $\mathrm{NO}_{x}$ emissions at 0 per cent EGR are lower than with thermal NO alone.

Due to the dilution of the mixture by the recirculated gases the maximum temperature in the cylinder decreases with increasing EGR rate. Although thermal NO production is reduced by more than a factor of ten, it is still the most important production path, even in the 53 per cent EGR case. Figure 3 indicates that now the prompt $\mathrm{NO}$ and nitrous $\mathrm{NO}$ paths significantly increase rather than reduce the NO concentration. This explains why the Magnussen model, which only accounts for thermal NO production, shows a stronger decrease of NO with increasing EGR rate.

This example demonstrates the necessity of using a comprehensive chemical mechanism for predictions of pollutant formation as in the RIF model. Once the model parameters for the spray and the scalar dissipation rate have been set for the baseline case ( 0 per cent EGR), the results for the other EGR rates were obtained with the same set of parameters. In contrast, for the eddy dissipation concept the ignition and combustion parameters had to be adjusted for each EGR rate.

The CPU (central processing unit) time needed for the RIF calculations was 120 hours on a CRAY J90, where $50 \mathrm{CPU}$ hours were needed by the computational fluid dynamics (CFD) code and $70 \mathrm{CPU}$ hours by the RIF code respectively. After both codes were optimized the CFD code was 10 times faster, consuming only 5 CPU hours, and the RIF code was 70 times faster, taking $1 \mathrm{CPU}$ hour.

Although using a simple surrogate fuel like $n$-heptane is instructive for fundamental research, it has some serious disadvantages when used in engines. It has very poor lubrication properties and therefore leads to severe wear of the fuel injection system. In addition, its physical and chemical properties are too different from real diesel. Hence, experiments with diesel cannot be compared to simulations using $n$-heptane. In addition, it was observed that in computations with only one flamelet the heat release in the partially premixed phase was too strong, leading to an overprediction of the mixing process which enhanced turbulence due to the too-rapid thermal expansion.

The latter problem was addressed by Barths et al. [7]. In this study $n$-decane was used in the experiments as well as in the simulations. Multiple flamelets were used, each attached to a marker particle which is convected through the flow field and thereby links the flamelet to an individual history of the flamelet parameters (pressure and scalar dissipation rate). Although $n$-decane is a better lubricant than $n$-heptane, its resemblance to diesel is still poor due to the lack of aromatic compounds.

This problem was resolved using a mixture of $n$-decane and $\alpha$-methyl-naphthalene as surrogate fuel. The liquid mixture consists of 70 per cent (liquid volume) $n$-decane and 30 per cent $\alpha$-methylnaphthalene. Its detailed chemical kinetics were thoroughly investigated in the IDEA-EFFECT program and will be called IDEA fuel in the following. The physical and chemical properties of the IDEA fuel and diesel are very similar. The densities at standard conditions are $817 \mathrm{~kg} / \mathrm{m}^{3}$ for the IDEA fuel and $840 \mathrm{~kg} / \mathrm{m}^{3}$ for diesel compared to $730 \mathrm{~kg} / \mathrm{m}^{3}$ for $n$-decane. The cetane number for diesel is 53 while it is 56 for the IDEA fuel.

Barths et al. [8] used this model and compared it to experiments conducted with diesel. The pollutant emissions ( $\mathrm{NO}_{x}$ and soot) of the simulations for full load agreed with the experimental results within a range of 8 per cent.

All the above-mentioned computations were performed simulating different versions of the VW TDI $1900 \mathrm{~cm}^{3}$ diesel engine. Hasse et al. [9] investigated the effect of post-injection in a large-bore diesel engine. $\mathrm{He}$ was able to reproduce the measured trends of an $\mathrm{NO}_{x}$ increase and a soot reduction. Hergart et al. [10] applied the RIF concept to the simulation of the Ford DIATA four-valve engine with $300 \mathrm{~cm}^{3}$ displacement per cylinder, equipped with a common rail injection system and turbocharger. He investigated the effect of varying injection timing and EGR.

In this study a detailed description of the representative interactive flamelet concept is given. Then the mathematical derivation for the Eulerian particle flamelet model (EPFM) as recently described by Barths et al. [11] is outlined. Experimental results comparing diesel and the IDEA fuel are subsequently discussed. The model is used to simulate an Audi DI diesel engine. A strategy for the subdivision of the computational domain into different flamelet subdomains is introduced and is then applied to the prediction of pollutant emissions caused by two injector nozzles having different flowrates. Finally, the effect of multiple flamelets on ignition, combustion and pollutant formation is described and discussed.

\section{Modelling Approach}

Crucial for reacting turbulent flows is the modelling of the chemistry. Here, a flamelet approach is 
employed in combination with a presumed beta probability density function ( $\beta$-PDF) whose shape is defined by the mean and the variance of the conserved scalar. The $\beta$-PDF has been found to be a good approximation for turbulent jets [12]. The methodology will be outlined in the following sections.

\subsection{CFD code}

The CFD code used in this study is KIVA-3V. It is documented in detail by Amsden [13]. Therefore, only differences from the original version will be described here.

The formation of the energy equation was changed from internal energy to enthalpy $H$, including the chemical heat of formation of the species $\Delta h_{\mathrm{f}}^{\circ}$ :

$$
\begin{aligned}
& H=\Delta h_{\mathrm{f}}^{\circ}+\int_{T^{0}}^{T} c_{p} \mathrm{~d} T \\
& \frac{\partial(\bar{\rho} \tilde{H})}{\partial t}+\nabla \cdot(\bar{\rho} \tilde{\boldsymbol{u}} \tilde{H})=\frac{\mathrm{D} \bar{p}}{\mathrm{D} t}-\nabla \cdot \overline{\boldsymbol{J}}+\bar{\rho} \tilde{\varepsilon}+\dot{Q}^{s}
\end{aligned}
$$

where $T$ is the temperature, $c_{p}$ is the specific heat of the mixture, $\bar{\rho}$ is the mean density, $\tilde{H}$ is the Favre mean enthalpy, $\tilde{u}$ is the velocity vector, $\bar{p}$ is the mean pressure, and $\tilde{\varepsilon}$ is the Favre mean viscous dissipation and the heat flux vector $\bar{J}$ is the sum of the contributions from heat conduction and the enthalpy flux term. No chemical source term appears in equation (2). The mean enthalpy $\tilde{H}$ is the sum over the species enthalpies $h_{i}$ weighted by the mean mass fraction $\tilde{Y}_{i}$ :

$$
\tilde{H}=\sum_{i=1}^{N} \tilde{Y}_{i} h_{i}(\tilde{T})
$$

From this equation, which neglects fluctuations around the mean values, the mean temperature is iteratively computed.

Substantial to the flamelet approach is the assumption that the species mass fractions are a function of one conserved, normalized scalar only, the mixture fraction $Z$. In order to determine the shape of the presumed PDF two equations for the mean mixture fraction $\tilde{Z}$ and its variance $\widetilde{Z^{\prime \prime 2}}$ are solved:

$$
\begin{aligned}
& \frac{\partial(\bar{\rho} \tilde{Z})}{\partial t}+\nabla \cdot(\bar{\rho} \boldsymbol{u} \tilde{Z})=\nabla \cdot {\left[\frac{\mu}{S c_{\tilde{Z}}} \nabla \tilde{Z}\right]+\dot{\rho}^{s} } \\
& \frac{\partial\left(\bar{\rho} \widetilde{Z^{\prime \prime 2}}\right)}{\partial t}+\nabla \cdot\left(\bar{\rho} \boldsymbol{u} \widetilde{Z^{\prime \prime 2}}\right)=\nabla \cdot\left[\frac{\mu}{S c_{\widetilde{Z^{\prime 2}}}} \nabla \widetilde{Z^{\prime \prime 2}}\right] \\
&+\frac{2 \mu}{S c_{\widetilde{Z^{\prime \prime 2}}}}(\nabla \tilde{Z})^{2}-\bar{\rho} \tilde{\chi}
\end{aligned}
$$

In equations (2), (4) and (5), $\dot{Q}^{\mathrm{s}}$ and $\dot{\rho}^{\mathrm{s}}$ represent the mean heat and mass transfer from droplets to the gaseous phase. They are determined by the spray model. The Schmidt numbers $S c_{\tilde{Z}}$ and $S c_{\widetilde{Z}^{\prime \prime 2}}$ are assumed to be constant. For the present study a value of 0.9 was taken for both. The source term in equation (5) accounting for mass transfer from the droplets was neglected. According to Gill et al. [14], it contributes by only 5 per cent.

Once equations (4) and (5) are solved in the CFD code the mean species mass fractions can be computed from

$$
\tilde{Y}_{i}(x, t)=\int_{0}^{1} \tilde{f}_{Z}(\eta ; x, t) Y_{i}(\eta, t) \mathrm{d} \eta
$$

where the presumed $\beta$-PDF $f_{Z}(\eta ; x, t)$ is determined by relating its two parameters to the local mean mixture fraction $\tilde{Z}(x, t)$ and the variance $\widetilde{Z^{\prime \prime 2}}(x, t)$. The mass fractions $Y_{i}(Z, t)$ are provided by the flamelet code, as will be discussed below.

\subsection{Laminar flamelets}

The laminar flamelet equations have been derived by Peters $[15,16]$, where local coordinate transformation and boundary layer arguments were used. In a recent publication [17] the derivation is generalized applying a two-scale asymptotic analysis. The resulting equations are

$$
\begin{gathered}
\rho \frac{\partial T}{\partial t}-\rho \frac{\chi}{2} \frac{\partial^{2} T}{\partial Z^{2}}-\rho \frac{\chi}{2} \frac{\partial T}{\partial Z} \frac{\partial c_{p}}{\partial Z}-\sum_{i}^{N} \rho \frac{\chi}{2 L e_{i}} \frac{c_{p_{i}}}{c_{p}} \frac{\partial Y_{i}}{\partial Z} \frac{\partial T}{\partial Z} \\
+\frac{1}{c_{p}} \sum_{i}^{N} \dot{m}_{i} h_{i}-\frac{1}{c_{p}} \frac{\partial p}{\partial t}-\frac{\dot{q}_{\mathrm{r}}}{c_{p}}=0
\end{gathered}
$$

and

$$
\rho \frac{\partial Y_{i}}{\partial t}-\rho \frac{\chi}{2 L e_{i}} \frac{\partial^{2} Y_{i}}{\partial Z^{2}}-\dot{m}_{i}=0
$$

In these equations $N$ denotes the number of chemical species, $c_{p_{i}}, \dot{m}_{i}, h_{i}, \dot{q}_{\mathrm{r}}, L e_{i}$ are the heat capacities at constant pressure, the chemical production rates, the enthalpies of the chemical species $i$, the radiative heat loss and the Lewis number of species $i$ respectively.

For equations (7) and (8) it is characteristic that after the transformation into space mixture fraction space the convective terms disappear. Since all scalars are convected with the same velocity in physical space no relative convective velocities exist between the mixture fraction and the other scalars such as species mass fractions or temperature. Coupling of the equations in phase space to the flow field in physical space occurs through the pressure $p$ and a particular parameter, the scalar dissipation rate 


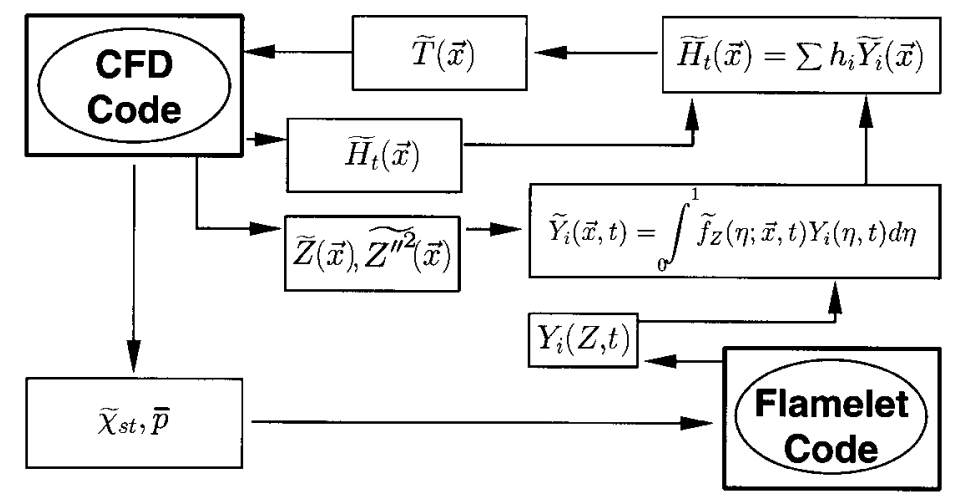

Fig. 4 Code structure of the representative interactive flamelet concept.

defined by

$$
\chi=2 D_{Z}(\nabla Z)^{2}
$$

The scalar dissipation rate represents instantaneous local diffusion and strain effects by the flow field [15]. In equations (7) and (8) it models the diffusive transport of the reactive scalars in mixture fraction space.

Unsteady flamelets were used first by Mauss et al. [18] to simulate flamelet extinction and re-ignition in a steady turbulent jet diffusion flame. In a diesel engine the turbulent flow and mixture fields are nonhomogeneous. Especially, the scalar dissipation rate will vary spatially and with time. The history of the scalar dissipation rate and the boundary conditions determine the solution of a flamelet, with the consequence that different flamelet histories must be calculated if these parameters vary too much in the physical domain.

\subsection{Eulerian particle flamelet model}

It is assumed that different marker particles are introduced which represent different flamelet histories depending on the path a particle takes through the turbulent flow field. The origin of a particle is denoted by $x_{0}$. Accounting for this additional dependence, equation (6) has to be changed to

$$
\tilde{Y}_{i}(x, t)=\int_{x_{0}} \int_{0}^{1} \tilde{f}_{Z, x_{0}}\left(\eta, x_{0}^{+} ; x, t\right) Y_{i}\left(\eta, x_{0}^{+}, t\right) \mathrm{d} \eta \mathrm{d} x_{0}^{+}
$$

Barths et al. [11] show that this equation can be written as

$$
\tilde{Y}_{i}(x, t)=\sum_{l=1}^{n_{l}} \tilde{I}_{l}(x, t) \int_{0}^{1} \tilde{f}_{Z}(\eta ; x, t) Y_{i, l}(\eta, t) \mathrm{d} \eta
$$

where $\tilde{I}_{l}(x, t)$ is the probability of finding a particle at location $x$ and time $t$ originating from region $x_{0, l}$.

Based on a PDF transport equation for the initial location $x_{0}$ an Eulerian transport equation for this probability $\tilde{I}_{l}(x, t)$ is derived [11]:

$$
\frac{\partial \bar{\rho} \tilde{I}_{l}}{\partial t}+\nabla \cdot\left(\bar{\rho} \tilde{\boldsymbol{v}} \tilde{I}_{l}\right)-\nabla \cdot\left(\bar{\rho} \frac{v_{\mathrm{T}}}{S c_{\mathrm{T}}} \nabla \tilde{I}_{l}\right)=0
$$

\subsection{RIF concept}

The coupling between the flow and mixture fraction fields and the flamelets is performed using the representative interactive flamelet (RIF) concept. The interaction between the CFD code and the flamelet code is shown schematically in Fig. 4. In the CFD code the equations for the flow, turbulence, the enthalpy, the mixture fraction and its variance are solved. The flamelet parameters $\tilde{\chi}_{\text {st }}$ and $\bar{p}$ are passed to the flamelet code. During one time step of the CFD code the flamelet code solves the unsteady flamelet equations with time steps that can be much smaller. In this way the time scales of the fluid dynamics and the chemistry are decoupled.

Conversely, the flamelet code calculates the species mass fractions $Y_{i}(Z, t)$ from which the mean values are computed using equation (11). The mean temperature is calculated using equation (3) with the local mean enthalpy $\tilde{H}$ taken from the solution of equation (2) and is finally passed to the CFD code.

For each flamelet a particle equation of the type of equation (12) has to be solved in the CFD code. Since these equations are of a simple convection-diffusion type, their solution results in only a small penalty in computational cost.

\subsection{Modelling of the flamelet parameters}

The parameters that have to be modelled in equations (7) and (8) are the pressure $p$ and the scalar dissipation rate $\chi$. In most low Mach number applications the pressure can be assumed to be spatially constant.

The $Z$ dependence of the scalar dissipation rate $\chi$ 
is taken from reference [15]:

$$
\chi(Z)=\frac{a}{\pi} \exp \left\{-2\left[\operatorname{erfc}^{-1}(2 Z)\right]^{2}\right\}=\frac{a}{\pi} f_{\text {erfc }}(Z)
$$

Assuming that the same dependence is valid for conditional mean scalar dissipation rates, $\chi$ in equations (7) and (8) can be expressed as

$$
\chi=\tilde{\chi}(Z, x, t)=\frac{\tilde{\chi}_{\mathrm{st}}(x, t)}{f_{\mathrm{erfc}}\left(Z_{\mathrm{st}}\right)} f_{\mathrm{erfc}}(Z)
$$

The mean value of the conditional scalar dissipation rate $\tilde{\chi}_{\mathrm{st}}(x, t)$, conditional at stoichiometric mixture, is obtained from

$$
\tilde{\chi}_{\mathrm{st}}=\frac{\tilde{\chi} f_{\text {erfc }}\left(Z_{\text {st }}\right)}{\int_{0}^{1} f_{\text {erfc }}(Z) \tilde{f}_{\mathrm{Z}}(\eta) \mathrm{d} \eta}
$$

where $\tilde{\chi}$ is the sink term appearing in equation (5) which is modelled as (cf. reference [19])

$$
\tilde{\chi}=c_{\chi} \tilde{\varepsilon} \widetilde{\tilde{k}} \widetilde{Z^{\prime \prime 2}}
$$

where $c_{\chi}=2.0$. A surface-averaged value for the scalar dissipation rate at stoichiometric mixture for each flamelet is computed following Pitsch et al. [20] by converting the surface integrals into volume integrals. Here it is weighted additionally with the probability of finding particle $l$ :

$$
\widehat{\chi_{\mathrm{st}}}(l)=\frac{\int_{V} \tilde{I}_{l}(x) \bar{\rho}(x) \tilde{\chi}_{\mathrm{st}}^{3 / 2}(x) \tilde{f}_{\mathrm{Z}}\left(Z_{\mathrm{st}}\right) \mathrm{d} V^{\prime}}{\int_{V} \tilde{I}_{l}(x) \bar{\rho}(x) \tilde{\chi}_{\mathrm{st}}^{1 / 2}(x) \tilde{f}_{\mathrm{Z}}\left(Z_{\mathrm{st}}\right) \mathrm{d} V^{\prime}}
$$

\subsection{Surrogate fuel}

The behaviour of the surrogate fuel IDEA as compared to diesel fuel with respect to emissions was investigated using a Volkswagen transparent DI 1900 diesel engine. The pollutant concentrations $\left(\mathrm{NO}_{x}\right.$ and soot) in the exhaust gas were measured by Antoni [21]. The exhaust gas analysis was carried out using standard exhaust instrumentation and a heated gas probing valve and line positioned just downstream of the exhaust valve. The soot probing technique was the Bosch method applying a Bosch smokemeter and $\mathrm{NO}_{x}$ probing was carried out with a chemiluminescence analyser (CLD).

For the thermodynamic measurements of the in-cylinder pressure a standard water-cooled piezoelectric pressure transducer (KISTLER 601, sensitivity $16 \mathrm{pC} /$ bar) was used, which was mounted instead of a cylinder liner side window. At TDC (top dead centre) this location is in the crevice region. Due to this positioning the measured pressure traces are disturbed by pipe oscillations.

The similarity between diesel and IDEA fuel results in an almost identical behaviour of both fuels concerning vaporization, ignition and heat release. This is shown in Fig. 5, where the measured cylinder pressures versus crank angle are plotted for both fuels. The start of injection is at $11^{\circ} \mathrm{CA}$ BTDC (before top dead centre). The injected fuel mass is $16 \mathrm{mg}$. The pressure traces are hardly distinguishable, proving the similarity.

Figures 6 and 7 show the dependence of the pollutant formation on injected fuel mass for both fuels. In these figures the exhaust gas values are plotted versus torque rather than injected fuel mass, since the injected fuel mass was not measured on-line with the experiments, but the torque was. The start of injection (SOI) was at $11^{\circ} \mathrm{CA}$ BTDC. In all cases

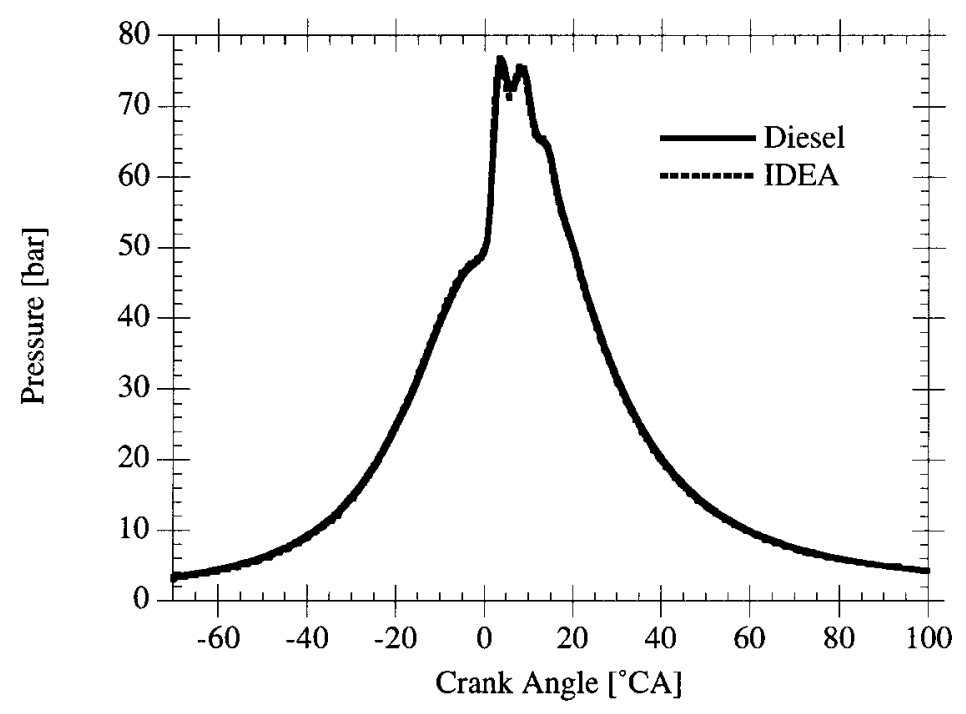

Fig. 5 Comparison of the pressures obtained for diesel and IDEA fuel. 


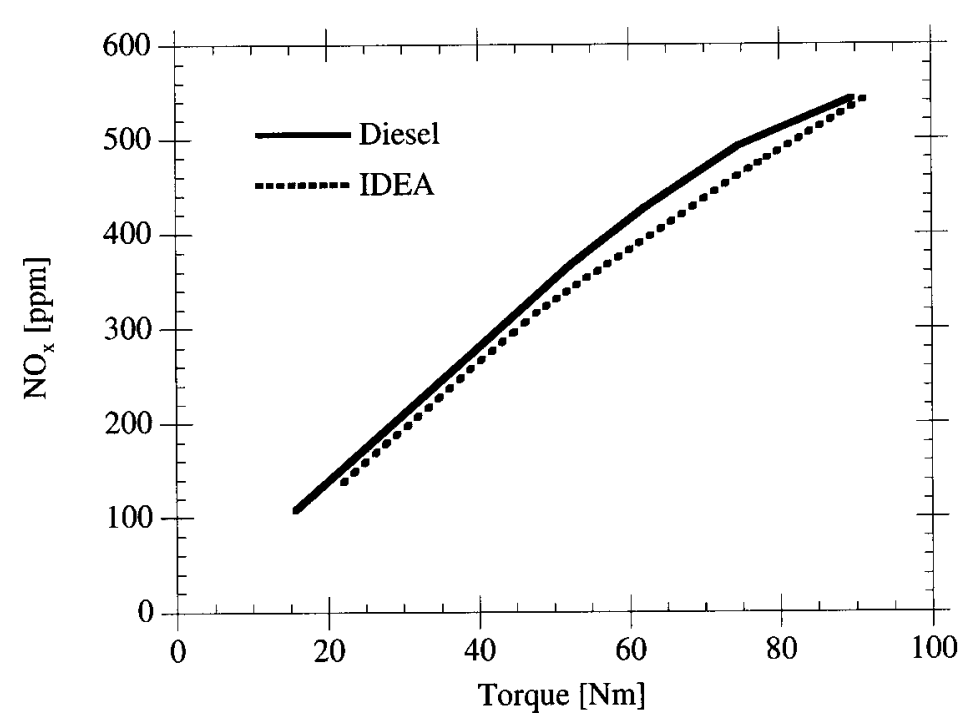

Fig. 6 Exhaust gas values of $\mathrm{NO}_{x}$ for diesel and IDEA fuel.

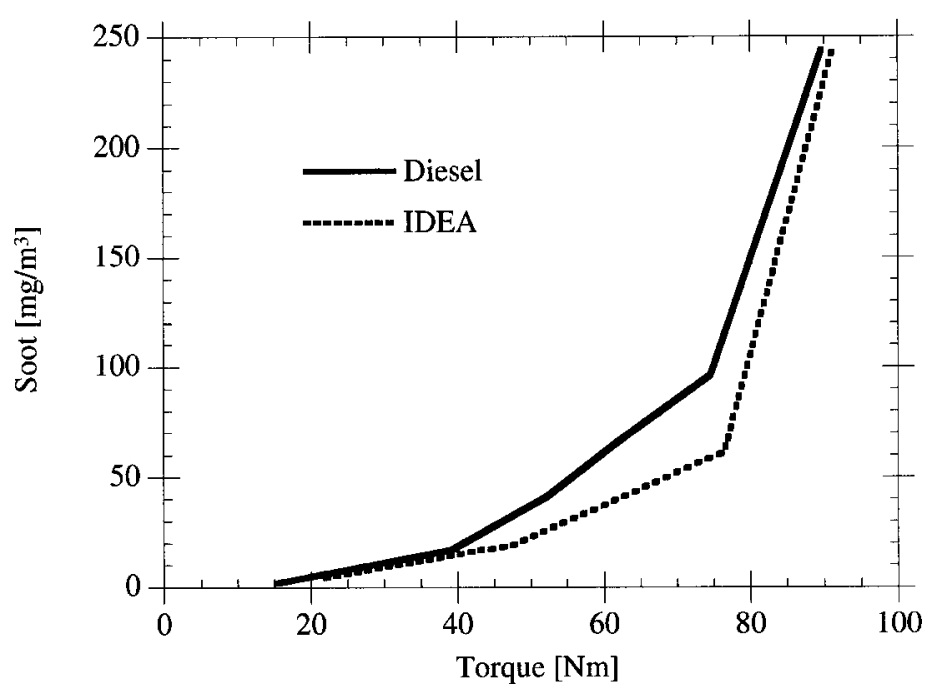

Fig. 7 Exhaust gas values of soot for diesel and IDEA fuel.

ignition occurred at TDC. Figure 6 reveals an almost linear increase of the $\mathrm{NO}_{x}$ in the exhaust gas with increasing torque. The gradient for diesel and IDEA is the same, with slightly higher absolute values for diesel (difference of 3-7 per cent).

The soot mass concentration increases approximately exponentially with increasing torque for diesel and IDEA, as displayed in Fig. 7. In the range of the torque between 40 and $80 \mathrm{~N}$ m IDEA produces 30 per cent less soot than diesel, whereas the deviation for higher and lower loads is around only 10 per cent.

\subsection{Chemistry model}

The complete chemical reaction mechanism for $n$-decane and $\alpha$-methyl-naphthalene comprises 519 elementary reactions and 109 chemical species. This mechanism describes low-temperature auto-ignition and combustion as well as formation of soot precursors and $\mathrm{NO}_{x}$. The $n$-decane mechanism was taken from Pitsch and Peters [22], the $\mathrm{C}_{1}-\mathrm{C}_{2}$ and $\mathrm{O} / \mathrm{H}$ chemistry has mainly been taken from Baulch et al. [23], while low-temperature kinetic rate data have been taken from Benson [24] and Chevalier et al. [25]. The $\mathrm{NO}_{x}$ submechanism taken from Hewson and Bollig [26] accounts for thermal, prompt and nitrous oxide contributions to $\mathrm{NO}_{x}$ formation and for $\mathrm{NO}_{x}$ reburn by hydrocarbon radicals and amines $\left(\mathrm{NH}_{x}\right)$. Soot precursor chemistry is described up to benzene following Mauss [27] based on Frenklach and Warnatz [28] and Miller and Melius [29] and simplified by Pitsch [30]. Further formation and growth of small polycyclic aromatic hydrocarbons (PAHs) is included in the mechanism up to PAHs consisting of four aromatic rings.

The formation, the growth and the oxidation of 
soot particles is described by a kinetically based model. A method using statistical moments is employed [27, 31].

\section{Experiments}

The investigated engine is a one-cylinder version of the Audi V6 TDI 2.5 litre engine. The only difference is in the shape of the piston bowl, which is flat in order to allow for optical access through a quartz glass window in the piston. The injection system is of a common-rail type with a piezo injector instead of the common solenoid injector. This allows for fast control of the injection rate.

The injection rate was measured on a separate test rig using the Bosch EMMI device. Comparing the measured needle lift obtained from the test rig and the engine shows very good agreement. This allows the injection rate from the test rig to be used for the engine simulation. The spray parameters were set as given in Table 1. The injection rates were taken from the test rig measurements. Since cavitation was observed in the measurements, the effective nozzle area was reduced to 80 per cent of the actual nozzle area.

The experiments were carried out using regular diesel fuel. The pressure was measured using an AVL GM 11 G-90 transducer. The intake air was conditioned and the mass flowrate was determined by an Aerzner device (type 7A). Exhaust gas samples were taken $4.2 \mathrm{~m}$ behind the exhaust valves in order

\begin{tabular}{|ll|}
\hline Model & Audi TDI \\
Displacement volume & $416 \mathrm{~cm}^{3}$ \\
Bore & $78.3 \mathrm{~mm}$ \\
Stroke & $86.4 \mathrm{~mm}$ \\
Connecting rod length & $158.0 \mathrm{~mm}$ \\
Piston crown & Flat \\
Compression ratio & $19.5: 1$ \\
Injection system & Common-rail \\
& with piezo injector \\
Nozzle type A & \\
Nozzle holes & 5 \\
Flowrate & $730 \mathrm{~cm}^{3} / \mathrm{min}$ \\
Hole diameter & $0.16 \mathrm{~mm}$ \\
Nozzle type B & \\
Nozzle holes & 5 \\
Flowrate & $600 \mathrm{~cm} / \mathrm{min}$ \\
Hole diameter & $0.14 \mathrm{~mm}$ \\
Rail pressure & $700 \mathrm{bar}$ \\
Spray angle & $142^{\circ}$ \\
Engine speed & $1500 \mathrm{r} / \mathrm{min}$ \\
Mass flow of air & $21.6 \mathrm{~kg} / \mathrm{h}$ \\
Injected mass & $10 \mathrm{mg}$ \\
SOl & $3 \mathrm{CA}^{\circ} \mathrm{ATDC}$ \\
\hline
\end{tabular}

Table 1 Engine data. to determine the pollutant concentrations $\left(\mathrm{NO}_{x}\right.$ and soot). $\mathrm{NO}_{x}$ was measured with a chemiluminescence analyser (Horiba Mexa $9100 \mathrm{H}$ ). For soot probing the Bosch method was applied (AVL Smokemeter 409).

\section{Simulations}

The computations started at $180^{\circ}$ CA BTDC and ended $140^{\circ}$ ATDC at the point where the exhaust valve opens. The average cylinder pressure and air flowrate were set as measured. The wall temperatures $(450 \mathrm{~K})$ were set such that calculated and measured pressures matched during the compression phase before injection started. The wall temperatures were held constant during the computations. The swirl was set to 0.5 times the number of revolutions of the engine $(\mathrm{r} / \mathrm{min})$, which corresponds to the measured swirl. The injection nozzle was located on the axis of symmetry. Therefore, only a sector of $72^{\circ}$ with periodic boundaries was simulated in favour of computational resources. The number of grid cells at TDC was 35 in the radial, 24 in the azimuthal and 17 in the axial directions. This corresponds to a mesh resolution of $1 \mathrm{~mm}$ in the radial and axial directions and $3^{\circ}$ in the azimuthal direction. The mesh is displayed in Fig. 8.

The spray parameters was set as given in Table 1 . The injection rates were taken from the test rig measurements. Since cavitation was observed in the measurements, the effective nozzle area was reduced to 80 per cent of the actual nozzle area.

\subsection{Ignition of diffusion flames}

The criteria that are applied for the subdivision of the flamelets will now be discussed. Figure 9, taken from Pitsch and Peters [32], shows schematically the

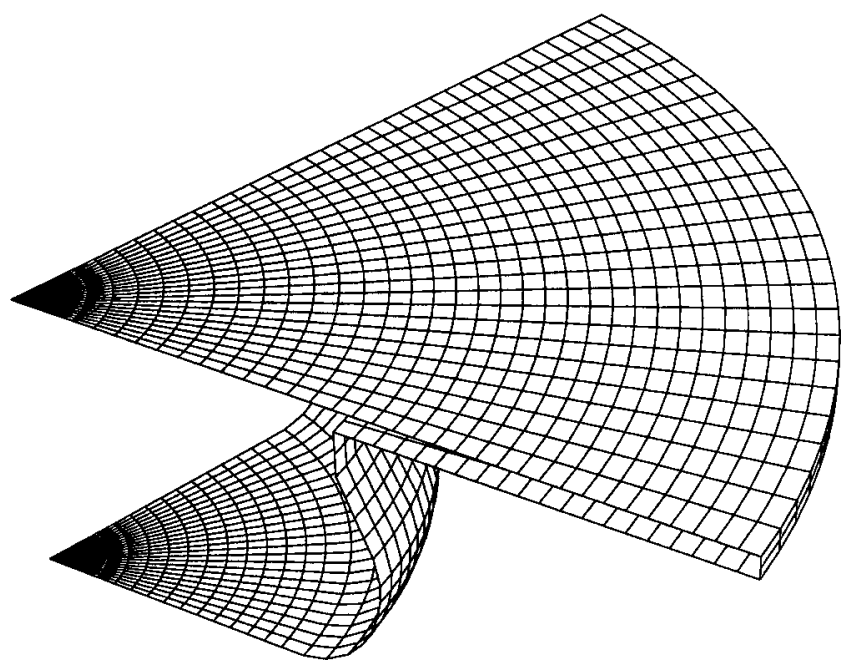

Fig. 8 Numerical mesh. 


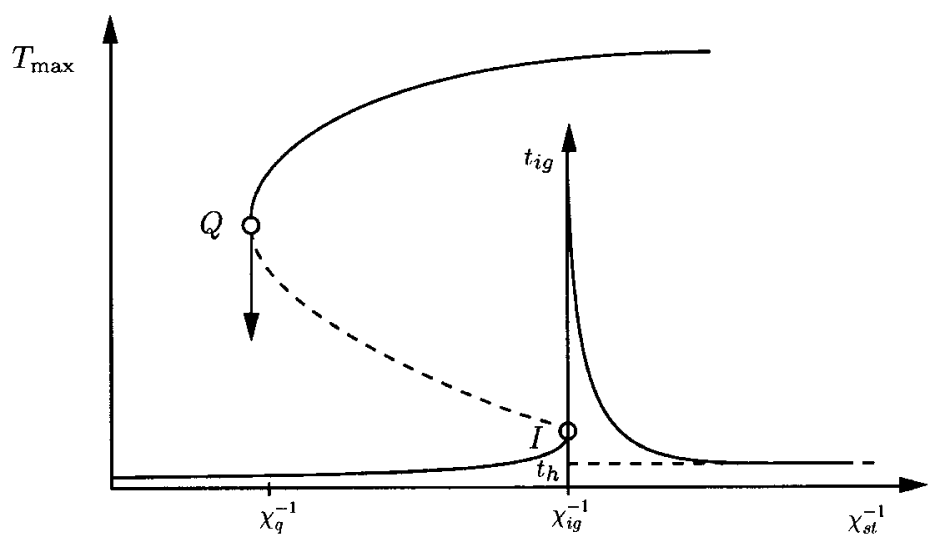

Fig. 9 Ignition and quenching in diffusion flames.

maximum temperature of a steady diffusion flame as a function of the inverse of the scalar dissipation rate (S-shaped curve). Depending on the initial conditions, two stable solution branches are possible between the points denoted by $\mathrm{Q}$ for quenching and I for ignition. Starting from unburnt initial conditions and decreasing the scalar dissipation rate (SDR) from a value that is higher than $\chi_{\mathrm{ig}}$, the maximum temperature rises only marginally. For those conditions the diffusive transport in mixture fraction space is so strong that only cool flames can develop, but thermal runaway is prevented. For SDRs lower than $\chi_{\mathrm{ig}}$ thermal runaway is possible and a steady state solution will finally be obtained on the upper branch of the S-shaped curve.

The time-scales of the chemistry in a burning diffusion flame are much smaller than the time-scales during ignition. Therefore, the SDR can be increased beyond $\chi_{\mathrm{ig}}$ before the extinction limit denoted by $\chi_{\mathrm{q}}$ is reached. Under diesel engine conditions $\chi_{\mathrm{ig}}$ and $\chi_{\mathrm{q}}$ differ by more than one order of magnitude.

Figure 9 also contains a graph which shows schematically the dependence of the ignition delay time on the SDR for an unsteady diffusion flame. At the ignition limit $\left(\chi_{\mathrm{ig}}\right)$ the ignition delay time is infinity. It decreases rapidly with decreasing SDR and for small SDR approaches asymptotically the ignition delay time in a homogeneous reactor.

In diesel engines the SDR will initially be infinity for the first fuel drop when injection starts. It then decreases as the mixture field homogenizes. Since the mixture is unburnt initially, ignition can first occur after the SDR decreases below the ignition limit. Therefore, the history of the SDR becomes more important the closer the SDR is to the ignition limit.

The relation between the scalar dissipation rate and the ignition process is investigated in more detail in the following. Figure 10 displays schematically the behaviour of the temperature where a step function of the SDR was imposed on an initially unburnt unsteady flamelet. The initial and boundary conditions correspond to typical diesel engine conditions. At first the SDR (broken line) was held above the ignition limit $\left(\chi_{\text {initial }}=125 \mathrm{~s}^{-1}\right)$. After $2 \mathrm{~ms}$ it was lowered to $0 \mathrm{~s}^{-1}\left(\chi_{\text {final }}\right)$. The corresponding

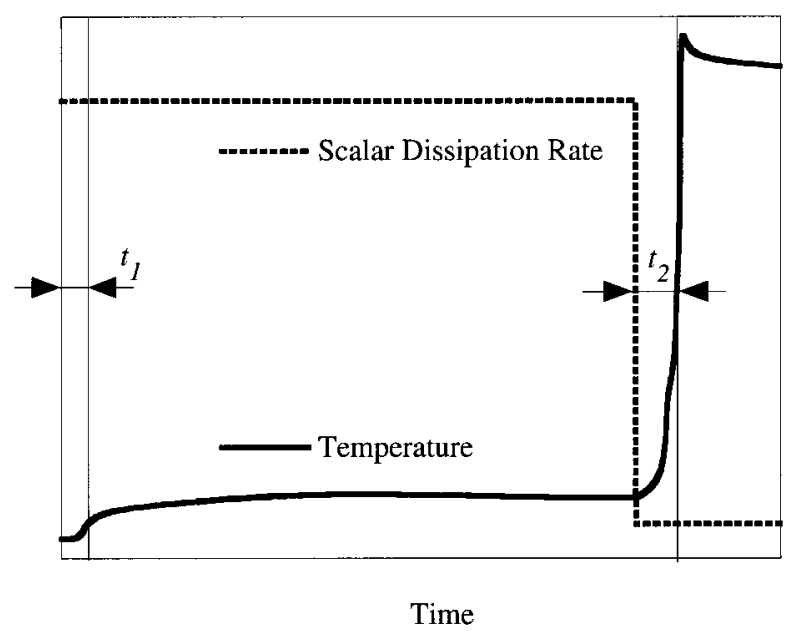

Fig. 10 Illustration of the two time-scales for cool flames and thermal runaway. 
temperature profile at a value of $Z=0.1$ is represented by the full line. Two characteristic timescales can be identified. The first $\left(t_{1}\right)$ is defined by the time interval up to the maximum temperature gradient appearing during the first stage of the temperature increase (cool flame). The second time-scale $\left(t_{2}\right)$, describing thermal runaway, is the time to reach a temperature of $1500 \mathrm{~K}$ needed after the SDR is lowered to $\chi_{\text {final }}$.

This numerical experiment was repeated for increasing values of $\chi_{\text {final }}$ until the ignition limit was reached. The resulting ignition delay times $t_{2}$ are plotted in Fig. 11. Under these conditions the ignition limit for the SDR is approximately $106 \mathrm{~s}^{-1}$. The minimum ignition delay time is $t_{2} \approx 0.1$ and occurs at $\chi_{\text {final }}=0$. The same experiments were repeated for an initial SDR $\left(\chi_{\text {initial }}\right)$ of $250 \mathrm{~s}^{-1}$, but the ignition delay times $t_{2}$ changed only marginally.

In a second set of numerical experiments the relation between the time-scale of the cool flame $\left(t_{1}\right)$ and the SDR $\left(\chi_{\text {initial }}\right)$ was investigated for the same initial and boundary conditions. In this case the SDR was held constant on its initial value. It was found that $t_{1}$ is rather independent from the SDR, ranging from 0.06 to $0.075 \mathrm{~s}$ as the SDR varies from 0 to $250 \mathrm{~s}^{-1}$.

It is therefore concluded that the history of the SDR is not important for the flamelets as long as the decreasing SDR is above the ignition limit for more than $t_{1}$, which usually is the case in diesel engines.

\subsection{Subdivision into different flamelet regions}

Figure 12 shows the evolution of the SDR for a computation using ten flamelets. After injection starts at $3^{\circ}$ CA ATDC the SDR increases rapidly due to turbulence induced by the fuel spray.

Since the mixture field must first evolve with the start of injection, initially only one flamelet is

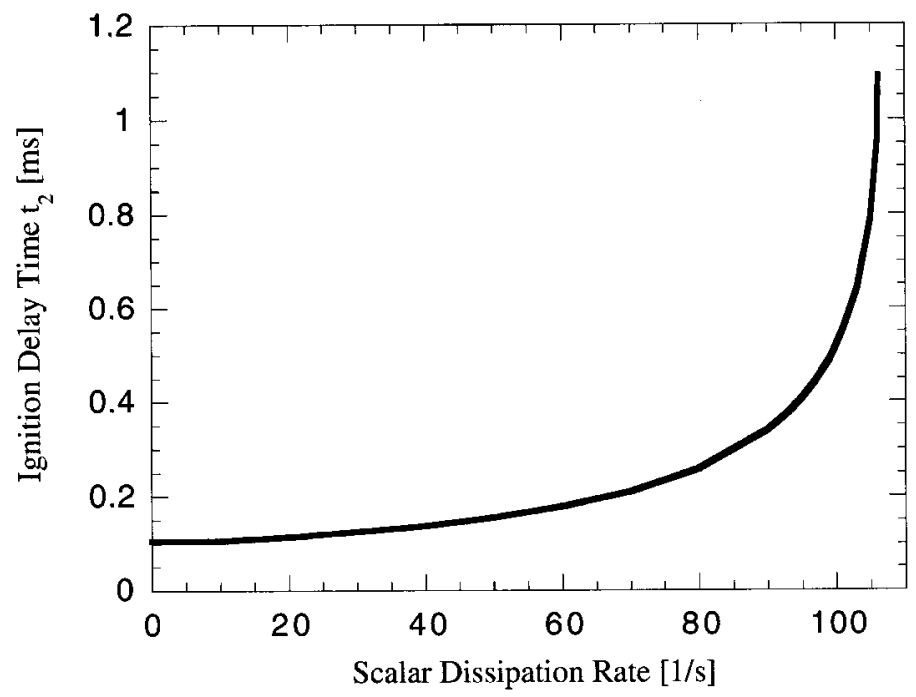

Fig. 11 Time-scale $t_{2}$ for the thermal runaway as a function of the scalar dissipation rate.

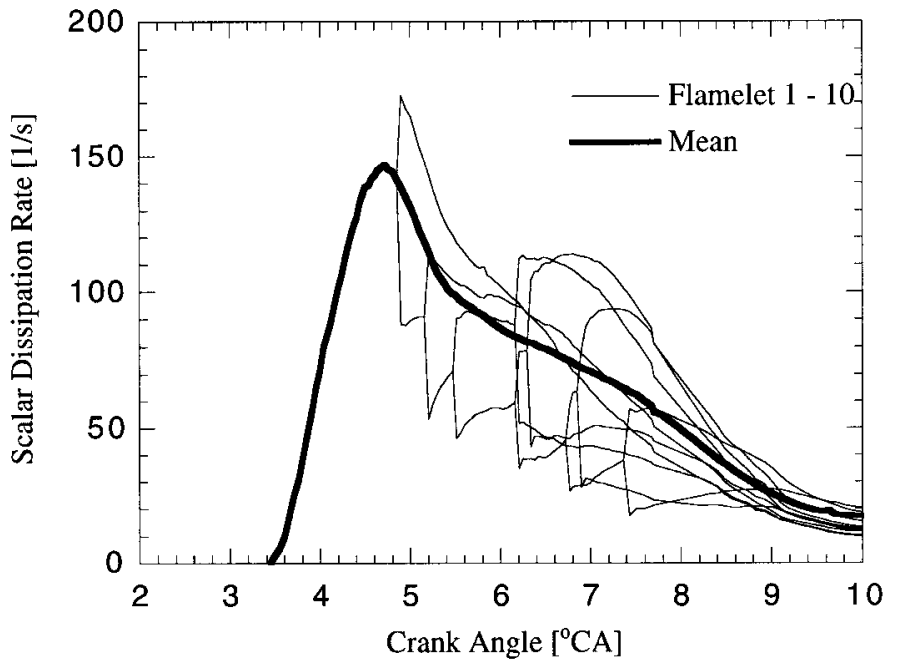

Fig. 12 Evolution of the scalar dissipation rates for the different flamelets. 
representative for the whole computational domain. The probability $\tilde{I}_{1}$ of finding flamelet 1 is therefore one everywhere and equation (12) does not yet need to be solved. With the evolving mixture field the SDR starts to vary spatially. When this variation exceeds a certain limit the flamelet is subdivided. This limit was set to a standard deviation of 15 per cent for all the SDR values found in the computational domain. Since only a limited number of flamelets is feasible at reasonable computational costs three more constraints for the subdivision were imposed to guarantee a meaningful distribution of flamelets. The first is that subdivision is first allowed when the SDR starts to decrease. Moreover, flamelets that contain less mass than $0.5 / n_{\max }$ times the total mass in the domain are not allowed to be subdivided (where $n_{\max }$ is the maximum number of flamelets). Finally, the portion of stoichiometric mixture within the flamelets being subdivided must be larger than $0.5 / n_{\mathrm{r}}$, with $n_{\mathrm{r}}$ the number of flamelets present.

These criteria are fulfilled at $4.9^{\circ} \mathrm{CA}$ ATDC and flamelet 1 is subdivided for the first time. All regions where the SDR is larger than mean value of the former flamelet domain are attributed to the new flamelet. In the regions the probability of finding the new flamelet is set equal to the probability of finding the former flamelet $\left(\tilde{I}_{2}=\tilde{I}_{1}\right)$ and the probability of finding the former flamelet is then equal to zero $\left(\tilde{I}_{1}=0\right)$. In regions where the SDR is lower than the mean value the probability of finding the new flamelet is set to zero $\left(\tilde{I}_{2}=0\right)$ and the probability of finding the former flamelet remains the same. Then for both flamelets new mean SDRs are computed. The PDFs of the SDR for the whole domain and the two flamelets are displayed in Fig. 13 at $0.1^{\circ} \mathrm{CA}$ after the first subdivision. The two ranges of the SDR that are covered by the two flamelets are clearly distinguished. Due to the turbulent mixing process they start to overlap and the variance of the SDR increases for each flamelet subdomain until the next subdivision proceeds. This process is repeated until the variance of the SDR in the individual flamelet subdomains is low enough and the mean value is able to represent the SDR of that flamelet.

\subsection{Combustion and pollutant formation}

In Fig. 14 the mean cylinder pressure is plotted for the experiment with injector type A (dotted line), a simulation with ten flamelets (thick line) and a simulation with one flamelet (thin line). By the time ignition occurs ( $7^{\circ}$ CA ATDC) the SDRs of the flamelets vary strongly between 20 and $110 \mathrm{~s}^{-1}$. Thus, the flamelets ignite consecutively, corresponding to the level of their SDRs, and the pressure for the simulation with ten flamelets follows very closely

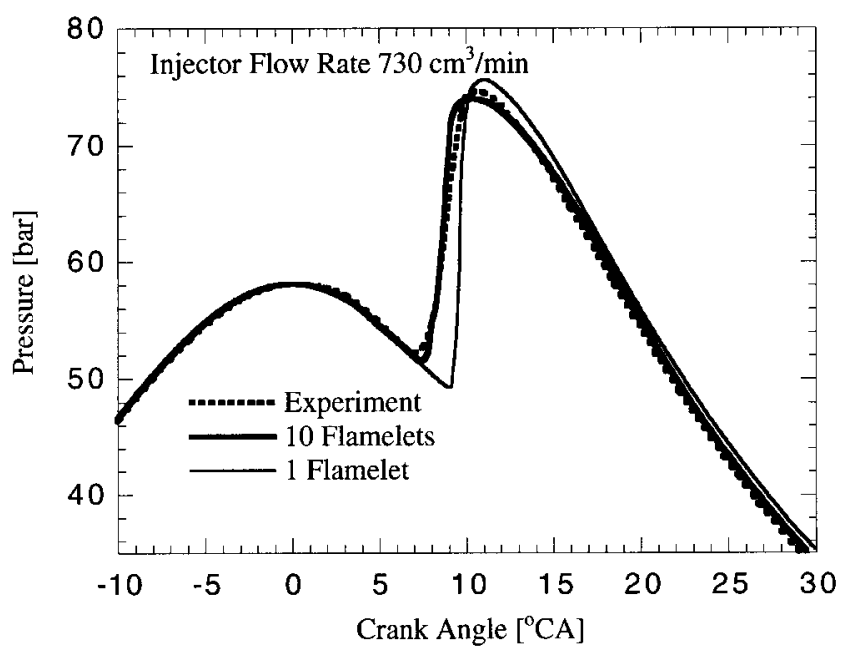

Fig. 14 Cylinder pressure as a function of crank angle for injector type A.

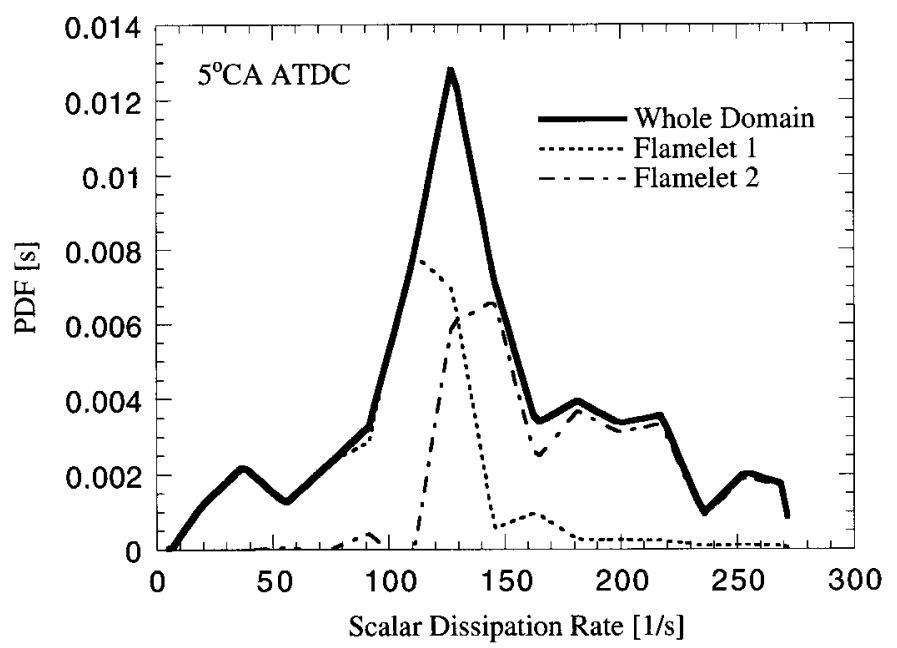

Fig. 13 Probability density function of the scalar dissipation rate after the first subdivision. 
the measured curve. Simulations using 20 and 50 flamelets were also performed, but the pressure was hardly distinguishable from the one with ten flamelets and is therefore not explicitly shown. In the simulation with one flamelet, ignition is delayed by $2^{\circ} \mathrm{CA}$. Because all the partially premixed part of the mixture ignites simultaneously the heat release is much stronger, resulting in a steep pressure gradient. The strong heat release also induces enhanced turbulent mixing due to thermal expansion. Therefore, the pressure is overpredicted when using only one flamelet.

This also has consequences for the pollutant predictions, as can be seen in Table 2. The $\mathrm{NO}_{x}$ level with 10, 20 and 50 flamelets is reproduced excellently. The deviation is less than 5 per cent. A lower value for $\mathrm{NO}_{x}$ is expected since in the experiments diesel was used, while the simulations were performed using the IDEA fuel which produces slightly less $\mathrm{NO}_{x}$, as was shown in Fig. 6 . The soot emissions of this engine are very low. The simulations with 10 , 20 and 50 flamelets predict half of the measured soot value. Considering the complexity of soot formation and oxidation as well as experimental uncertainties, this also can be considered as a good result. The difference between the pollutant predictions for the cases with 20 and 50 flamelets are below 0.1 per cent for both $\mathrm{NO}_{x}$ and soot. With one flamelet, $\mathrm{NO}_{x}$ is overpredicted by 20 per cent while the soot level is even lower than with multiple flamelets. Both trends can be attributed to the stronger mixing in the simulations using only one flamelet; this is caused by the very rapid heat release in the case with one flamelet, which leads to a likewise strong expansion. As a consequence the turbulence intensity $u_{\mathrm{T}}$ rises more strongly than in the more realistic case with multiple flamelets. This is documented in Fig. 15, which shows the cylinder-averaged values for the turbulence intensity $\left(u=k^{0.5}\right)$ and the integral length scale $\left(L=k^{1.5} / \varepsilon\right)$ for one and ten flamelets respectively. Again, the individual results for multiple flamelets $(10,20,50)$ are visually not discernible. The first increase of the turbulence intensity is generated by the injected fuel. Initially the turbulence intensity is the same for both cases until ignition $\left(7^{\circ} \mathrm{CA}\right.$ ATDC) occurs in the case with ten flamelets. Then the decrease of the turbulence intensity is moderately slower than with one flamelet. When ignition $\left(9^{\circ} \mathrm{CA}\right.$ ATDC) occurs in the case with one flamelet the turbulence intensity rises until $10.5^{\circ} \mathrm{CA}$ ATDC, where it again starts to decay. Afterwards its level remains higher than in the case with ten flamelets. In contrast the turbulent integral length scale $L$ is practically the same in both cases. Since the tubulent viscosity is

\begin{tabular}{|c|c|c|c|c|}
\hline \multirow{2}{*}{$\begin{array}{l}\text { Injector } \\
\text { flowrate }\end{array}$} & \multicolumn{2}{|l|}{ Type A $\left(730 \mathrm{~cm}^{3} / \mathrm{min}\right)$} & \multicolumn{2}{|l|}{ Type B $\left(600 \mathrm{~cm}^{3} / \mathrm{min}\right)$} \\
\hline & $\mathrm{NO}_{x}\left(\mathrm{NO}, \mathrm{NO}_{2}\right)(\mathrm{ppm})$ & Soot $\left(\mathrm{mg} / \mathrm{m}^{3}\right)$ & $\mathrm{NO}_{x}\left(\mathrm{NO}, \mathrm{NO}_{2}\right)(\mathrm{ppm})$ & Soot $\left(\mathrm{mg} / \mathrm{m}^{3}\right)$ \\
\hline Experiment & 621 & 0.6 & 573 & 0.1 \\
\hline 1 flamelet & $732(556,176)$ & 0.2 & - & - \\
\hline 10 flamelets & $625(484,141)$ & 0.34 & $548(433,115)$ & 0.33 \\
\hline 20 flamelets & $604(472,132)$ & 0.31 & - & - \\
\hline 50 flamelets & $604(472,132)$ & 0.31 & - & - \\
\hline
\end{tabular}

Table 2 Pollutant concentrations in the exhaust gas.

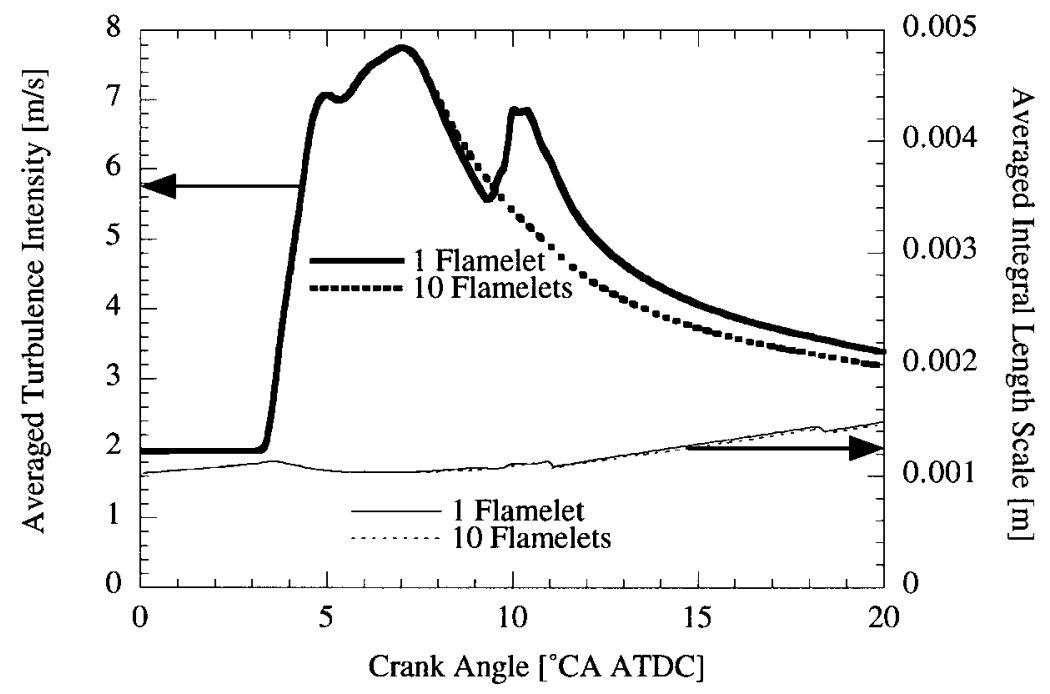

Fig. 15 Cylinder-averaged turbulence intensity and integral length scale. 
defined by $v=L u$, the mixing process is faster with one flamelet than with multiple flamelets, leading to a stronger heat release and a higher pressure.

With the same criteria for the flamelet subdivision a simulation for injector type B (flowrate of $600 \mathrm{~cm}^{3} / \mathrm{min}$ ) was performed using ten flamelets. The pressure trace ploted in Fig. 16 again agrees well with the measured one. The maximum is slightly higher in the simulation. The time of ignition is predicted exactly. The predicted $\mathrm{NO}_{x}$ value is $548 \mathrm{ppm}$ compared to $573 \mathrm{ppm}$ in the experiment (Table 2). This corresponds to a difference of approximately 5 per cent. The soot prediction of $0.33 \mathrm{mg} / \mathrm{m}^{3}$ is higher than the measured value. Comparing the two types of injectors, it is interesting to note that, whereas the $\mathrm{NO}_{x}$ predictions give quantitatively reliable results within 5 per cent deviation, the soot predictions only attain the order magnitude of the measurements. Moving from nozzle type A to B there is a decrease of the soot mass concentration in the exhaust gas while the predictions do not follow this trend. This behaviour will be investigated in more detail below.

The different histories of the flamelets are shown in Figs 17 and 18. Three temperature profiles in mixture fraction space corresponding to flamelets 1, 2 and 7 are displayed at $7.5^{\circ} \mathrm{CA}$ ATDC, where ignition occurs, and at $8.5^{\circ}$ CA ATDC. In Figs 17 and 18 the value of $\chi_{\text {st }}$ is lowest for flamelet 1 and highest for flamelet 7 . The value of $\chi_{\text {st }}$ for flamelet 2 represents approximately the average value in the combustion chamber. According to equations (7) and (8), the diffusive transport in mixture fraction space for the flamelets is proportional to the value of $\chi_{\mathrm{st}}$. Therefore, a low value of $\chi_{\text {st }}$ is equivalent to a low heat loss and low radical transport from the reaction zone, resulting in an earlier temperature rise. At $7.5^{\circ}$ CA ATDC, $\chi_{\text {st }}$ is low enough to allow flamelet 1 to ignite. Under diesel engine conditions ignition occurs

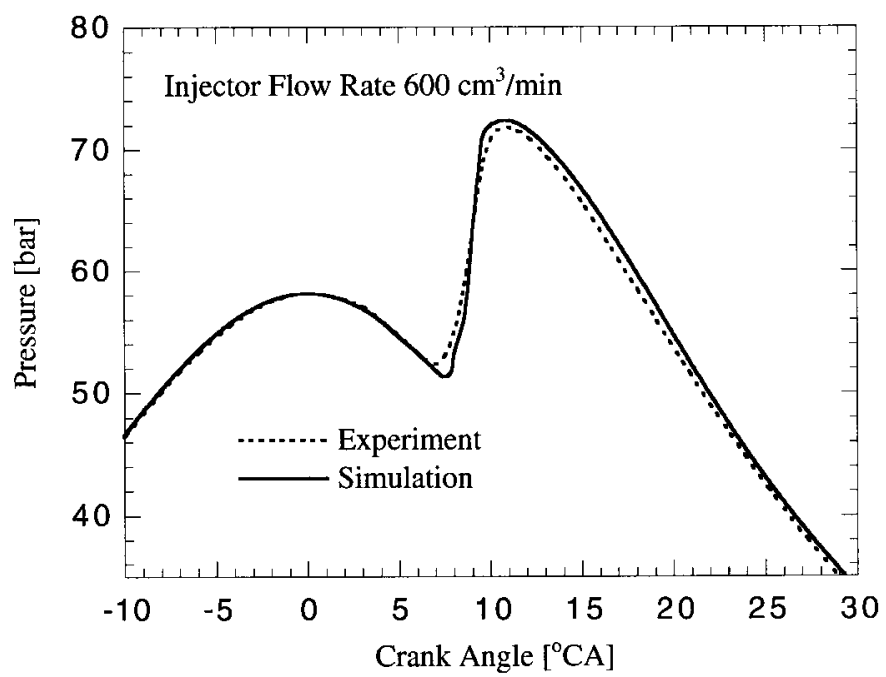

Fig. 16 Cylinder pressure as a function of crank angle for injector type B.

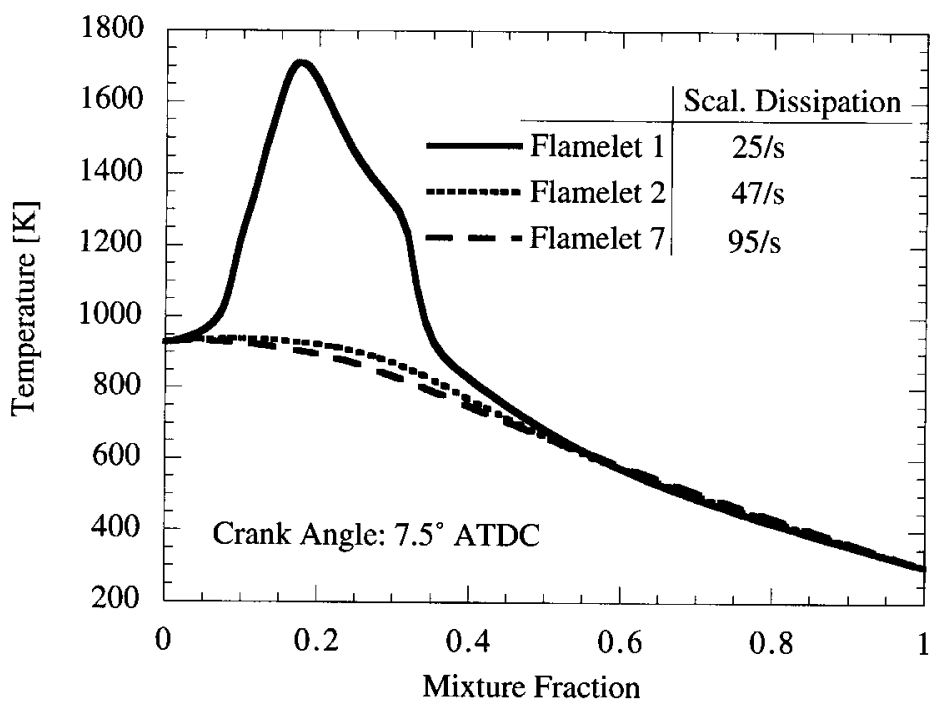

Fig. 17 Temperature in different flamelets at $7.5^{\circ} \mathrm{CA}$ ATDC. 


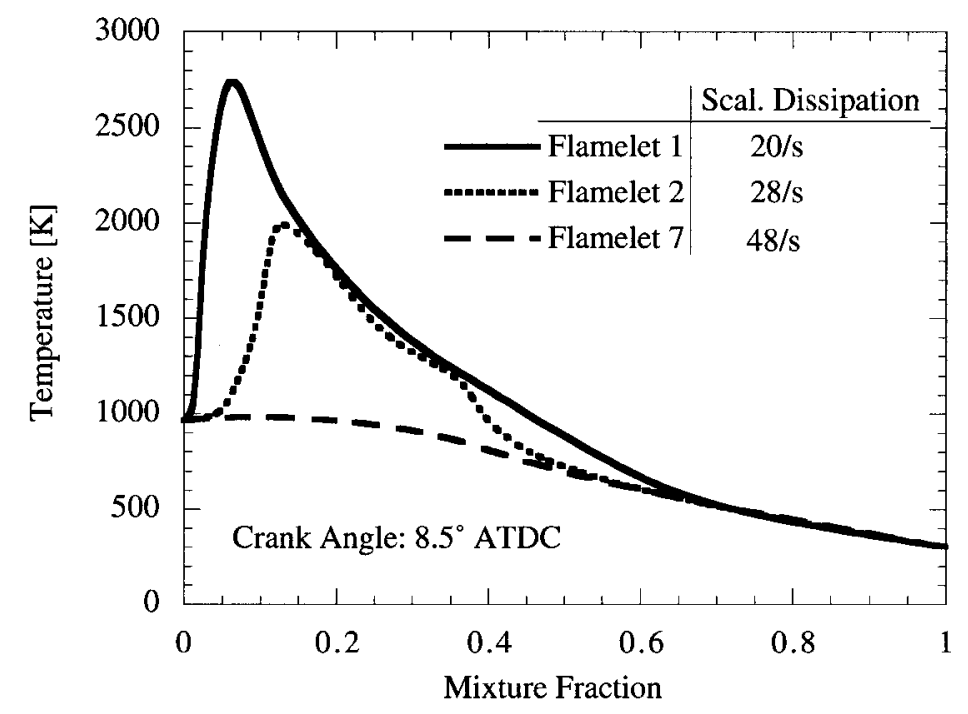

Fig. 18 Temperature in different flamelets at $8.5^{\circ} \mathrm{CA}$ ATDC.

in the rich part of the flame $(Z \approx 0.2)$. The value of $\chi_{\text {st }}$ in flamelet 2 has reached a level where cool flame burning is possible, and, hence, a moderate temperature rise can be observed compared to flamelet 7 , where $\chi_{\text {st }}$ is still too high for any temperature rise in the flamelet.

At $1^{\circ} \mathrm{CA}$ later flamelet 1 has fully ignited over nearly the entire mixture fraction range between $Z=0$ and $Z=1$ and has reached nearly the adiabatic flame temperature (Fig. 18). Flamelet 2 has ignited and is approximately in the state that flamelet 1 was in $1^{\circ} \mathrm{CA}$ earlier. For flamelet $7, \chi_{\text {st }}$ is still too high for a visible temperature rise. This process of consecutive ignition of the flamelets is responsible for the gradual pressure rise as displayed in Fig. 14.

The effect of multiple flamelets on pollutant predictions is investigated in Figs 19 and 20. The NO and soot concentration profiles of the same flamelets
(1, 2 and 7) are shown at $140^{\circ}$ CA ATDC. Although the level of $\chi_{\text {st }}$ is low and hardly differs for the different flamelets, significant deviations of the NO mass fractions in the flamelets are found. The relative difference between the maximum mass fraction of flamelets 1 and 7 is 30 per cent and 10 per cent between flamelets 1 and 2 respectively. This is caused by two effects. Under conditions without exhaust gas recirculation the thermal $\mathrm{NO}$ formation path is predominant. It is strongly temperature dependent (increasing with increasing temperature). In a flamelet with an initially higher level of $\chi_{\text {st }}$ the temperature will be lower than in a flamelet with a low value of $\chi_{\text {st }}$. Therefore, there is a cumulative effect of temperature on NO formation. The NO formation by the thermal path will be lower in this flamelet with an initially higher level of $\chi_{\text {st }}$, and since NO consumption is negligible to leading order this results in a

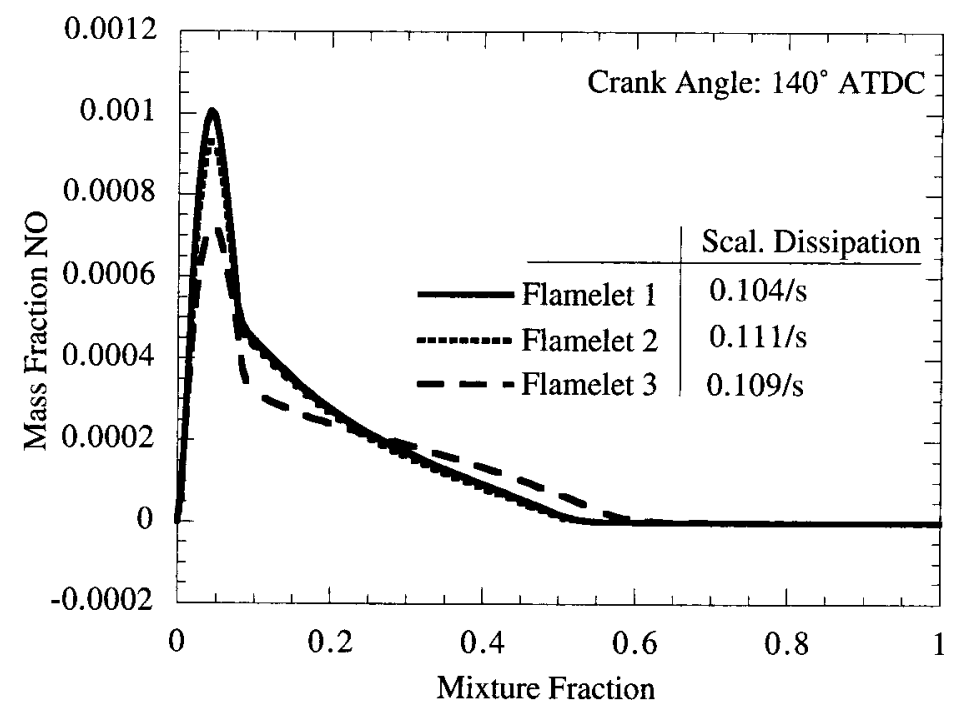

Fig. 19 NO mass fractions in different flamelets at $140^{\circ} \mathrm{CA}$ ATDC. 


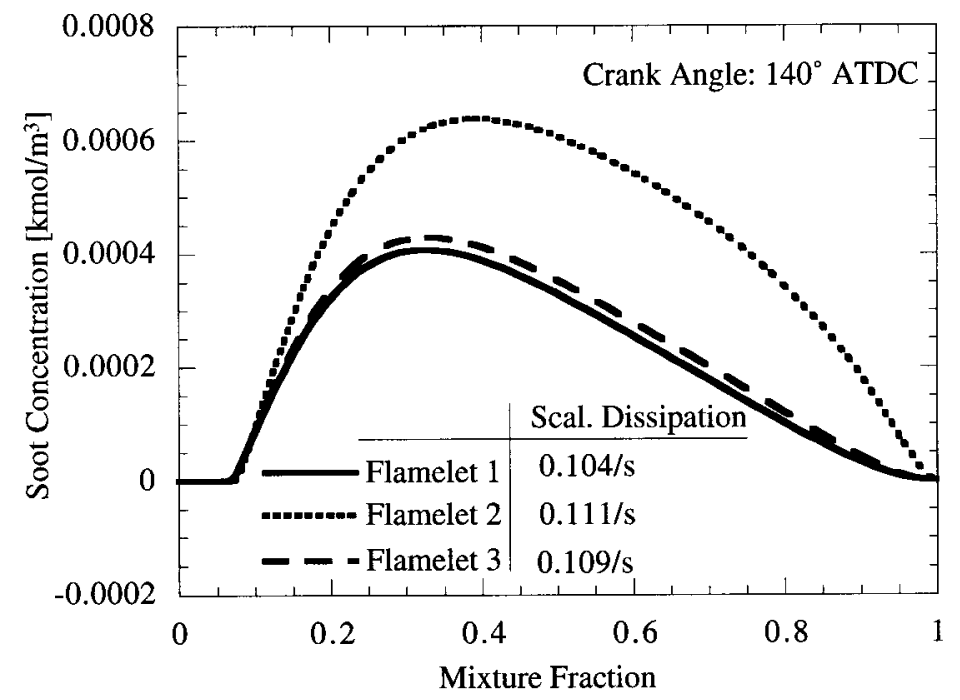

Fig. 20 Soot concentration in different flamelets at $140^{\circ} \mathrm{CA}$ ATDC.

lower overall NO level. The second effect is that in a flamelet that ignites earlier more time is available in the high-pressure and high-temperature phase around TDC. Hence, more NO is produced.

Even stronger differences in the resulting soot concentrations (35 per cent) are found. For the soot concentrations both formation and oxidation are equally important. Both processes are temperature dependent. Therefore, neither of them can be neglected, and simple correlations to the ignition delay time and the temperature level in the flamelet are not found. This is reflected in Fig. 20, where the soot concentration profile for flamelet 7 with the highest level of the scalar dissipation rate and the longest ignition delay time lies within the other two.

Figure 21 shows the profiles for the temperature, the first soot moment and the mass fraction of the $\mathrm{OH}$ radical as a function of the mixture fraction at $140^{\circ} \mathrm{CA}$ ATDC. The maximum of the $\mathrm{OH}$ mass frac- tion is located at stoichiometric mixture, where the temperature has its maximum as well. The $\mathrm{OH}$ mass fraction is still high enough to consume the soot completely and prevent it from diffusing to the lean side. This indicates that all soot in DI diesel engines might be consumed if the mixing after ignition is strong enough to shift the maximum mixture fraction in the engine below stoichiometric.

The soot mass concentrations in the exhaust gas also depend on the state of the mixture field when the exhaust valve opens. Figure 22 shows the massweighted PDF of the mixture fraction in the cylinder $140^{\circ}$ CA ATDC and the first soot moment in the mixture fraction space taken from a corresponding flamelet solution. The maximum mixture fraction is only slightly richer than stoichiometric $\left(Z_{\text {st }} \approx 0.065\right)$.

The profile of the first soot moment taken from the flamelet solution reveals that no soot is found for mixture fractions leaner than stoichiometric. This is

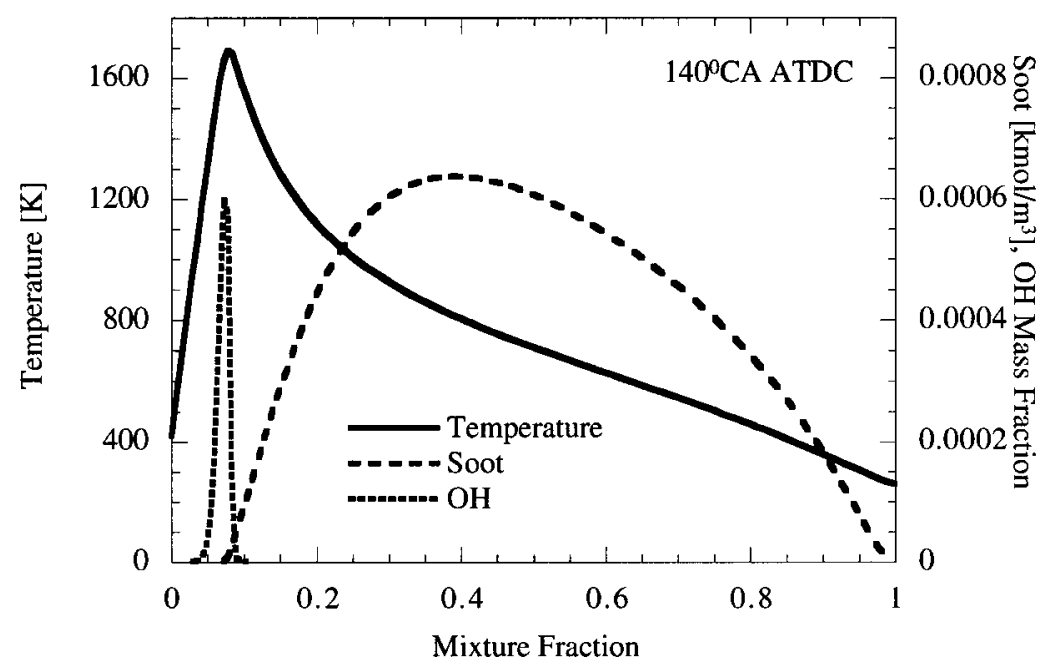

Fig. 21 Profiles of the temperature, $\mathrm{OH}$ and the first soot moment as a function of the mixture fraction. 


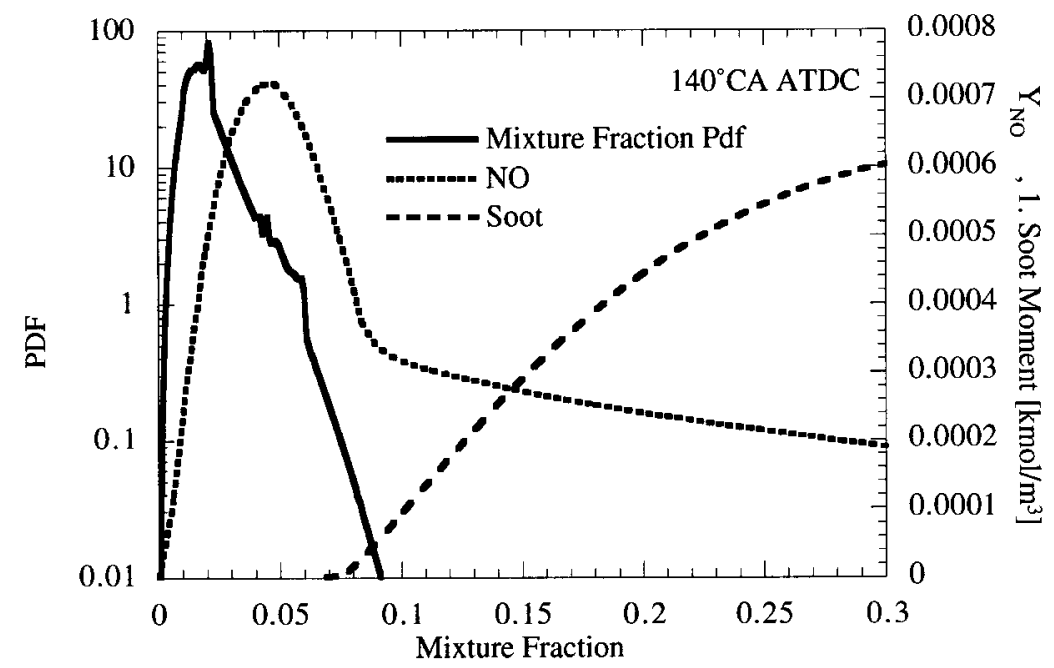

Fig. 22 PDF of the mixture fraction in the cylinder with the profiles of NO and the first soot moment as a function of the mixture fraction.

due to the still high temperature of approximately $1700 \mathrm{~K}$ and the still significant amount of $\mathrm{OH}$ radicals being present at stoichiometric mixture (Fig. 21). Since the soot mass concentration in the simulation is obtained by integrating the product of the PDF and the soot profile in the mixture fraction space, only the region where these profiles overlap contributes. Soot predictions become very sensitive to the shape of the PDF in this overlap region. In particular, this is the case when soot emissions are very low. In contrast, the overlapping region between the $\mathrm{NO}_{x}$ profile and the mixture PDF is significantly larger. Hence, the $\mathrm{NO}_{x}$ prediction is not as sensitive to the PDF of the mixture fraction.

It is important to note that the PDF used in Fig. 22 has been obtained as a mass-weighted sum of the $\beta$-PDF calculated from each grid cell. In Fig. 23 this distribution is compared to the distribution computed from the local mean values of the mixture fraction. The maximum value of the mean mixture fraction is below stoichiometric $\left(Z_{\text {st }}\right)$. Therefore, the portion of the mixture fraction PDF that generates the soot level is due to local mixture fraction fluctuations. This portion only contains 0.2 per cent of the total mass in the computational domain.

This shows that the prediction of the soot concentration in the exhaust gas is very sensitive to modelling assumptions. These concern not only the assumption of a $\beta$-PDF in each grid cell but also the turbulence models applied to obtain equations (4) and (5). Simplification of the modelling assumptions in these equations (i.e. gradient flux approximation, constant ratio of characteristic time-scales for scalar and turbulent kinetic energy dissipation, etc.) introduces uncertainties to which the extreme values mixture fraction are sensitive. In addition, local maxima

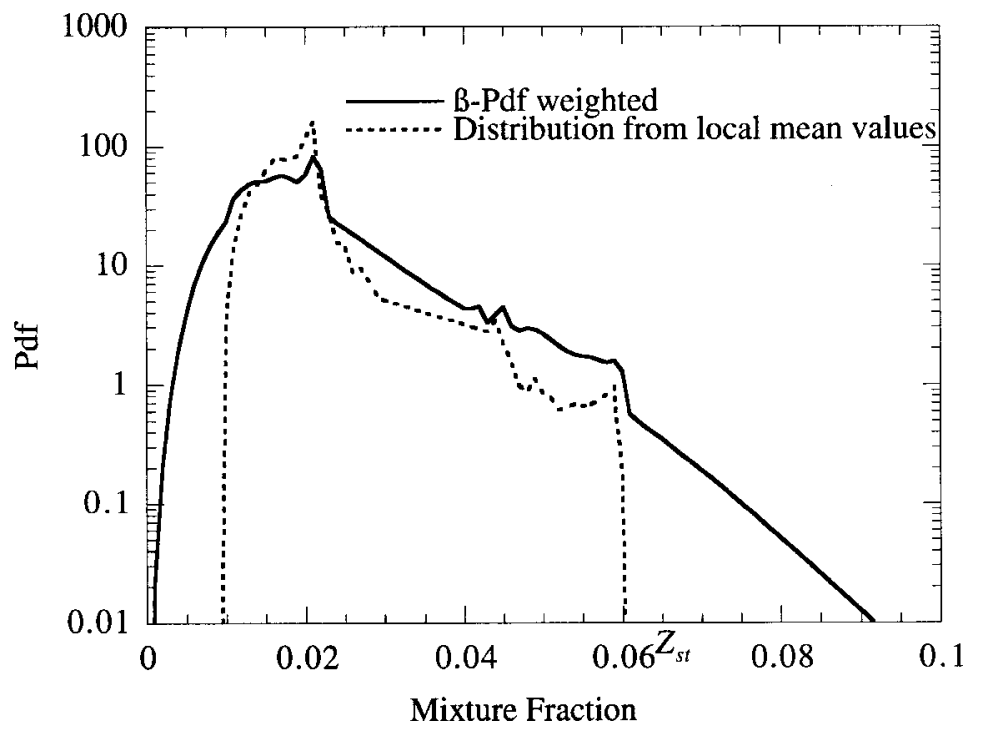

Fig. 23 Mixture distribution in the computational domain. 
(and minima) of the mean mixture fraction, which have a strong influence on the shape of the PDF in the overlap region, are subject to numerical diffusion due to discretization errors. The effect of both phenomena can be reduced by a higher mesh resolution. Unfortunately, this leads to a dilemma due to the well-known grid dependence of the spray model [33]. The evaporation rate diverges with increasing mesh resolution. Consequently, for each mesh resolution a different set of spray parameters has to be used in order to achieve the same results for the mixture field. The computational cost increases with increasing mesh resolution, which is in addition limited by hardware resources. Therefore, the cost of tuning becomes more and more prohibitive with increasing mesh resolution, although a higher accuracy is indicated for reliable soot predictions.

It should be noted that this is not a specific problem of flamelet modelling. It only becomes apparent because with this method mixing effects can be distinguished from chemical effects.

\section{Summary and Conclusion}

A mathematical derivation of the Eulerian particle flamelet model was outlined. The model was then applied to the simulation of an Audi DI diesel engine and a physically and numerically meaningful strategy for the distribution and subdivision of flamelets (particles) was given. The effect of the number of flamelets on the ignition delay time and the partially premixed burning phase, and subsequent pollutant formation were shown. A surrogate fuel, namely a mixture consisting of 70 per cent (liquid volume) $n$-decane and 30 per cent $\alpha$-methyl-naphthalene (IDEA fuel), was experimentally compared to diesel. Their resemblance in all relevant properties (density, cetane number, etc.) leads to an almost identical behaviour for ignition, combustion and pollutant formation.

The model was then used for the simulation of an Audi DI diesel engine. The simulations consumed 2340 CPU min in the CFD part and 20 CPU min for each flamelet on a CRAY J90 with SV1 processors.

For the prediction of the ignition delay time ten flamelets appear to be sufficient. The corresponding heat release rate (pressure gradient) was described to be significantly closer with ten flamelets as compared to only one. With a better description of these phenomena the pollutant predictions also improved significantly. Not much further improvement was achieved from using 20 and 50 flamelets. The differences for the results (pressure, $\mathrm{NO}_{x}$ and soot) between the simulations decrease with increasing number of flamelets showing converging behaviour.

The soot emissions show some quantitative deviations. The reasons for these deviations were investigated and it was shown that they are not specific to flamelet modelling, but can be attributed to uncertainties introduced by the modelling assumptions used for the mixture fraction field and numerical discretization errors.

The combustion strongly depends on the turbulent mixture field, which is again computed using various other submodels (spray, turbulence model, etc.) that are all non-linearly coupled and also introduce uncertainties. Therefore, the suggestion that, as with other more precise submodels, the spray model for instance, the prediction will show more sensitivity to an increase in the number of flamelets cannot be discounted.

\section{Acknowledgement}

This study has been supported by the Bayrische Forschungsstiftung (AZ:177/96) in the project: 'Potential neuartiger Einspritzverfahren zur Reduzierung von Ruß und $\mathrm{NO}_{x}$ bei der dieselmotorischen Verbrennung'.

\section{References}

1 Pitsch, H., Wan, Y. P. and Peters, N. Numerical investigation of soot formation and oxidation under diesel engine conditions. SAE Paper 952357, 1995.

2 Pitsch, H., Barths, H. and Peters, N. Three-dimensional modelling of $\mathrm{NO}_{x}$ and soot formation in DI-diesel engines using detailed chemistry based on the interactive flamelet approach. SAE Paper 962057, 1996.

3 Barths, H., Pitsch, H. and Peters, N. Comparison of the representative interactive flamelet model and the Magnussen model for combustion and pollutant formation in DI-diesel engines to experiments. In Proceedings of the 3rd International Conference on High Performance Computing in the Automotive Industry (Ed. M. Sheh), 1997.

4 Magnussen, B. F. and Hjertager, B. H. On mathematical modeling of turbulent combustion with special emphasis on soot formation and combustion. In Sixteenth Symposium (International) on Combustion, 1977, pp. 719-729 (The Combustion Institute, Pittsburgh, Pennsylvania).

5 Nishida, K. and Hiroyasu, H. Simplified three-dimensional modeling of mixture formation and combustion in a D.I. diesel engine. SAE Paper 890269, 1989.

6 Belardini, P., Bertoli, C., Ciajolo, A., D'Anna, A. and Del Giacomo, N. Three-dimensional calculations of DI diesel engine combustion and comparison with 
in-cylinder sampling valve data. SAE Paper 922225, 1992.

7 Barths, H., Antoni, C. and Peters, N. Threedimensional simulation of pollutant formation in a DI-diesel engine using multiple interactive flamelets. SAE Paper 982459, 1998.

8 Barths, H., Pitsch, H. and Peters, N. 3-D simulation of DI-diesel combustion and pollutant formation using a two-component reference fuel. Oil and Gas and Technology-Rev. IFP, 1999, 54(2), 233-244.

9 Hasse, C., Barths, H. and Peters, N. Modeling the effect of split injections in diesel engines using representative interactive flamelets. SAE Paper 1999-01-3547, 1999.

10 Hergart, C. A., Barths, H. and Peters, N. Modeling the combustion in a small-bore diesel engine using a method based on representative interactive flamelets. SAE Paper 1999-01-3550, 1999.

11 Barths, H., Hasse, C., Bikas, G. and Peters, N. Simulation of combustion in DI diesel engines using an Eulerian particle flamelet model. Submitted to TwentyEighth Symposium (International) on Combustion, 2000 (The Combustion Institute, Pittsburgh, Pennsylvania).

12 Jones, W. P. and McGuirk, J. Computation of a round turbulent jet discharging into a confined cross flow. In Second International Symposium on Turbulent Shear Flows, 1979, pp. 233-245.

13 Amsden, A. A. KIVA-3V: a KIVA program for engines with vertical or canted valves. Los Alamos National Laboratories Report LA-13313-MS, 1997.

14 Gill, A., Gutheil, E. and Warnatz, J. Numerical investigation of the combustion process in a direct-injection stratified charge engine. Combust. Sci. Technol., 1996, 115(4-6), 317.

15 Peters, N. Laminar diffusion flamelet models in nonpremixed turbulent combustion. Prog. Energy Combust. Sci., 1984, 10, 319-339.

16 Peters, N. Laminar flamelet concepts in turbulent combustion. In Twenty-First Symposium (International) on Combustion, 1987, pp.1231-1250 (The Combustion Institute, Pittsburgh, Pennsylvania).

17 Peters, N. Turbulent Combustion, 2000 (Cambridge Press).

18 Mauss, F., Keller, D. and Peters, N. A Lagrangian simulation of flamelet extinction and re-ignition in turbulent jet diffusion flames. In Twenty-Third Symposium (International) on Combustion, 1990, pp. 693-698 (The Combustion Institute, Pittsburgh, Pennsylvania).

19 Jones, W. P. and Whitelaw, J. H. Calculation methods for turbulent reacting flows: a review. Combust. Flame, 1982, 48, 1-26.

20 Pitsch, H., Chen, M. and Peters, N. Unsteady flamelet modelling of turbulent hydrogen/air diffusion flames. In Twenty-Seventh Symposium (International) on Combustion, 1998 (The Combustion Institute, Pittsburgh, Pennsylvania).

21 Antoni, C. Untersuchung des Verbrennungsvorgangs im direkteinspritzenden Dieselmotor mit zyklusaufgelöster Emissionsspektroskopie. PhD Thesis, RWTH Aachen, 1998

22 Pitsch, H. and Peters, N. Reduced kinetics of multicomponent fuels to describe the auto-ignition, flame propagation and post flame oxidation of gasoline and diesel fuels. Final Report, IDEA EFFECT, 1996.

23 Baulch, D. L., Cobos, C. J., Cox, R. A., Frank, P., Hayman, G., Just, Th., Kerr, J. A., Murrells, T., Pilling, M. J., Troe, J., Walker, R. W. and Warnatz, J. Evaluated kinetic data for cumbustion modelling. J. Phys. Chem. Ref. Data, 1992, 21, 411-429.

24 Benson, S. W. The kinetics of thermochemistry of chemical oxidation with application to combustion and flames. Prog. Energy Combust. Sci., 1981, 7, 125-134.

25 Chevalier, C., Louessard, P., Müller, U. C. and Warnatz, J. A detailed low-temperature reaction mechanism of $n$-heptane auto-ignition. In International Symposium on Diagnostics and Modeling of Combustion in Internal Engines, COMODIA 90, Kyoto, 1990 (The Japan Society of Mechanical Engineers).

26 Hewson, J. C. and Bollig, M. Reduced mechanisms for $\mathrm{NO}_{x}$ emissions from hydrocarbon diffusion flames. In Twenty-Sixth Symposium (International) on Combustion, 1996, pp. 2171-2180 (The Combustion Institute, Pittsburgh, Pennsylvania).

27 Mauss, F. Entwicklung eines kinetischen Modells der Rußbildung mit schneller Polymerisation. PhD Thesis, RWTH Aachen, 1997.

28 Frenklach, M. and Warnatz, J. Detailed modeling of PAH profiles in a sooting low-pressure acetylene flame. Combust. Sci. Technol., 1987, 51, 265-283.

29 Miller, J. A. and Melius, C. F. Kinetic and thermodynamic issues in the formation of aromatic compounds in flames of aliphatic fuels. Combust. Flame, 1992, 91, 21-39.

30 Pitsch, H. Modellierung der Zündung und Schadstoffbildung bei der dieselmotorischen Verbrennung mit Hilfe eines interaktiven Flamelet-Modells. PhD Thesis, RWTH Aachen, 1997.

31 Frenklach, M. and Harris, S. J. Aerosol dynamics modeling using the method of moments. J. Coll. Interface Sci., 1987, 118, 252-261.

32 Pitsch, H. and Peters, N. Investigation of the ignition process of sprays under diesel engine conditions using reduced $n$-heptane chemistry. SAE Paper 982464, 1998.

33 Krause, A. and Peters, N. Numerical simulation of transient diesel sprays with the CAS model. In ILASSEurope 99, 1999.

34 Lipkea, W. H. and DeJoode, A. D. Direct injection diesel engine soot modeling: formulation and results. SAE Paper 940670, 1994.

35 Roth, P., Brandt, O. and Gersum, S. V. High temperature oxidation of suspended soot particles verified by $\mathrm{CO}$ and $\mathrm{CO}_{2}$ measurements. In Twenty-Third Symposium (International) on Combustion, 1990, pp. 1485-1491 (The Combustion Institute, Pittsburgh, Pennsylvania).

\section{Appendix}

\section{The eddy dissipation concept}

A common feature of eddy dissipation models is the assumption that the chemical reactions are fast compared to the turbulent time-scale. Hence, the rate of combustion is controlled by the mixing on the molecular scale of fuel and oxygen eddies [4]. It is furthermore assumed that the rate of combustion is proportional to the mean fuel or oxygen concentration, depending on which one is deficient. Thus, if fuel is deficient, the rate of combustion $R_{\mathrm{c} 1}$ is given 
by

$$
R_{\mathrm{c} 1}=A \tilde{c}_{\mathrm{f}}\left(\begin{array}{l}
\tilde{\varepsilon} \\
\tilde{k}
\end{array}\right)
$$

where $\tilde{c}_{\mathrm{f}}$ denotes the mean fuel mass concentration, $\varepsilon$ the rate of dissipation of turbulent kinetic energy and $k$ the turbulent kinetic energy. For the case where oxygen is the deficient species, the mean fuel mass concentration $\tilde{c}_{\mathrm{f}}$ in equation (18) is replaced by the ratio of the mean oxygen mass concentration $\tilde{c}_{\mathrm{O}_{2}}$ and the stoichiometric oxygen requirement to burn $1 \mathrm{~kg}$ of fuel $r_{\mathrm{f}}$ :

$$
R_{\mathrm{c} 2}=A\left(\frac{\tilde{c}_{\mathrm{O}_{2}}}{r_{\mathrm{f}}}\right)\left(\begin{array}{l}
\tilde{\varepsilon} \\
\tilde{\tilde{k}}
\end{array}\right)
$$

A third equation is employed, which controls the early stage of combustion:

$$
R_{\mathrm{c} 3}=A B\left(\frac{\tilde{c}_{\mathrm{p}}}{1+r_{\mathrm{f}}}\right)\left(\begin{array}{c}
\tilde{\varepsilon} \\
\tilde{\tilde{k}}
\end{array}\right)
$$

Here $\tilde{c}_{\mathrm{p}}$ represents the mean mass concentration of the products. The rate of combustion is determined by the equation that gives the minimal value of the three above:

$$
R_{\mathrm{c}}=\min \left(R_{\mathrm{c} 1}, R_{\mathrm{c} 2}, R_{\mathrm{c} 3}\right)
$$

The proportionality factors $A$ and $B$ are parameters, which need to be adapted.

For the ignition model in conjunction with the Magnussen model a one-step global reaction for $n$-heptane is applied:

$$
n-\mathrm{C}_{7} \mathrm{H}_{16}+11 \mathrm{O}_{2} \rightarrow 7 \mathrm{CO}_{2}+8 \mathrm{H}_{2} \mathrm{O}
$$

The rate of fuel consumption is determined by an
Arrhenius expression:

$$
R_{\text {global }}=A_{\text {global }} \tilde{C}_{\mathrm{f}}^{0.5} \tilde{c}_{\mathrm{O}_{2}}^{1.5} \exp \left(\frac{E_{\text {global }}}{R_{\text {gas }} \tilde{T}}\right)
$$

Again, the parameters, which need to be tuned to obtain the right ignition delay time, are the preexponential factor $A_{\text {global }}$ and the activation energy $E_{\text {global }} \cdot R_{\text {gas }}$ denotes the universal gas constant and $\tilde{T}$ is the temperature. When 1 per cent of the total fuel mass is consumed, the model is switched and the rate of combustion is determined using equation (21).

The $\mathrm{NO}_{x}$ formation is described only by the extended Zel'dovic mechanism, the thermal reaction path. This is quite a good approximation, at least for computations where no exhaust gas is recirculated, as discussed below.

Soot formation is simulated using the Hiroyasu model [5]. It consists of two global reactions, one for the soot formation [equation (24)] and one for the oxidation [equation (25)]. Although it is well known that soot does not stem from fuel molecules directly, the soot formation is related to the fuel mass as a first approximation [34]:

$$
\frac{\mathrm{d} m_{\mathrm{s}}}{\mathrm{d} t}=A_{\mathrm{sf}} m_{\mathrm{fv}} \bar{p}^{0.5} \exp \left(\frac{E_{\mathrm{sf}}}{R_{\mathrm{gas}} \tilde{T}}\right)
$$

with the mass of soot $m_{\mathrm{s}}$, the fuel vapour mass $m_{\mathrm{fv}}$ and the pressure $p$. Similarly, the oxidation of soot proceeds almost exclusively by hydroxyl radicals [35], but is approximated as being proportional to the mole fraction of molecular oxygen $\mathrm{X}_{\mathrm{O}_{2}}$ :

$$
\frac{\mathrm{d} m_{\mathrm{s}}}{\mathrm{d} t}=-A_{\mathrm{so}} m_{\mathrm{s}} \tilde{X}_{\mathrm{O}_{2}} \bar{p}^{1.8} \exp \left(\frac{E_{\mathrm{so}}}{R_{\mathrm{gas}} \tilde{T}}\right)
$$

The values for the parameters of the soot model $\left(A_{\mathrm{sf}}\right.$, $A_{\mathrm{so}}, E_{\mathrm{sf}}$ and $\left.E_{\mathrm{so}}\right)$ are taken from the literature [6]. 